\title{
Membrane-Anchored Hairless Protein Restrains Notch Signaling Activity
}

\author{
Dieter Maier $\mathbb{D}$ \\ Deptartment of General Genetics 190g, University of Hohenheim, Garbenstr. 30, 70599 Stuttgart, Germany; \\ dieter.maier@uni-hohenheim.de
}

Received: 25 September 2020; Accepted: 4 November 2020; Published: 6 November 2020

\begin{abstract}
The Notch signaling pathway governs cell-to-cell communication in higher eukaryotes. In Drosophila, after cleavage of the transmembrane receptor Notch, the intracellular domain of Notch (ICN) binds to the transducer Suppressor of Hairless $(\mathrm{Su}(\mathrm{H}))$ and shuttles into the nucleus to activate Notch target genes. Similarly, the Notch antagonist Hairless transfers $\mathrm{Su}(\mathrm{H})$ into the nucleus to repress Notch target genes. With the aim to prevent $\mathrm{Su}(\mathrm{H})$ nuclear translocation, Hairless was fused to a transmembrane domain to anchor the protein at membranes. Indeed, endogenous $\mathrm{Su}(\mathrm{H})$ co-localized with membrane-anchored Hairless, demonstrating their binding in the cytoplasm. Moreover, adult phenotypes uncovered a loss of Notch activity, in support of membrane-anchored Hairless sequestering $\mathrm{Su}(\mathrm{H})$ in the cytosol. A combined overexpression of membrane-anchored Hairless with $\mathrm{Su}(\mathrm{H})$ lead to tissue proliferation, which is in contrast to the observed apoptosis after ectopic co-overexpression of the wild-type genes, indicating a shift to a gain of Notch activity. A mixed response, general de-repression of Notch signaling output, plus inhibition at places of highest Notch activity, perhaps reflects $\mathrm{Su}(\mathrm{H})$ 's role as activator and repressor, supported by results obtained with the Hairless-binding deficient $\mathrm{Su}(\mathrm{H})^{\mathrm{LL}}$ mutant, inducing activation only. Overall, the results strengthen the idea of $\mathrm{Su}(\mathrm{H})$ and Hairless complex formation within the cytosolic compartment.
\end{abstract}

Keywords: notch signaling; suppressor of hairless; Hairless; Drosophila; membrane-anchor; sequestration; repressor complex; transcriptional regulation

\section{Introduction}

The development of eukaryotic animals depends on a multitude of developmental decisions underlying cellular differentiation, triggered by several signaling pathways. One example is the Notch signaling pathway that allows communication amongst neighboring cells. Name-giving to this pathway is the receptor Notch, a large transmembrane protein, which is activated by binding to its transmembrane ligands, named Delta and Serrate in Drosophila, that are presented on the adjacent cell. Consequently to the activation, the intracellular domain of Notch (ICN) is cleaved and released into the cytosol of the responding cell [1]. Intriguingly, ICN itself plays an important role in signal transduction. Firstly, it is involved in the nuclear translocation of the transcription factor Suppressor of Hairless $(\mathrm{Su}(\mathrm{H}))$ whereby binding occurs in the cytosol [2-4]. Secondly, it acts as a transcriptional coactivator of $\mathrm{Su}(\mathrm{H})$ in conjunction with other co-factors in an activator complex [5-9]. Indeed, activator complex formation is highly conserved throughout the animal kingdom [10-12].

Likewise, Drosophila $\mathrm{Su}(\mathrm{H})$ is extremely well-conserved in structure and function with its vertebrate and invertebrate orthologues of the CSL family [13-15]. CSL is the abbreviation for human CBF1 (C-promoter Binding Factor 1, also named RBPJ for recombination signal-binding protein for immunoglobulin kappa J region), Drosophila $\mathrm{Su}(\mathrm{H})$, and the nematode Caenorhabditis elegans protein Lag1 (abnormal cell LINeage-12 (Lin-12) and abnormal germ-line proliferation phenotype-1 (Glp-1)). For example, murine RBPJ is $80 \%$ identical to Drosophila $\mathrm{Su}(\mathrm{H})$ at the amino acid level [14]. In fact, 
RBPJ can even largely replace $\mathrm{Su}(\mathrm{H})$ activity in the fly $[16,17]$. CSL transcription factors all share three functional domains: the $\mathrm{N}$-terminal domain (NTD) and the $\beta$ trefoil domain (BTD) contact the DNA, whereas the BTD and the C-terminal domain (CTD) contact ICN [8,18-20]. CSL proteins in general act as a molecular switch, since they not only serve as transcriptional activators of Notch target genes, but also as repressors in the absence of signal. In this case, CSL assembles repressor complexes on Notch target gene promoters $[5,21]$. However, repression mechanisms are more diverged: in Drosophila, the central player is Hairless $(\mathrm{H})$, which functions as an adaptor in the repressor complex, binding $\mathrm{Su}(\mathrm{H})$ as well as the general co-repressors Groucho and C-terminal binding protein, eventually resulting in gene silencing [22-25].

Hairless binds with nanomolar affinity to the C-terminal domain of $\mathrm{Su}(\mathrm{H})[26,27]$. The crystal structure of the repressor complex revealed that the Hairless protein inserted deeply between two $\beta$ sheets into the $\mathrm{CTD}$ of $\mathrm{Su}(\mathrm{H})$, thereby distorting the $\mathrm{Su}(\mathrm{H})$ structure in a way that precludes the binding of $\mathrm{ICN}$ to $\mathrm{Su}(\mathrm{H})$ [27]. Apart from the novelty of the binding, the analysis showed that $\mathrm{Su}(\mathrm{H})$ exclusively binds either ICN or Hairless. Earlier experiments have revealed that excess ICN was able to displace $\mathrm{H}$ from $\mathrm{Su}(\mathrm{H})-\mathrm{H}$ complexes, indicating a certain degree of competition in the formation of activator or repressor complexes, respectively [26]. This competition most likely occurs in the cytoplasm, the place of ICN generation, because not only ICN, but also Hairless, shuttles $\mathrm{Su}(\mathrm{H})$ in the nucleus $[3,28,29]$. Accordingly, despite its function as a transcriptional repressor, Hairless is not strictly nuclear but also present in the cytoplasm, where it binds to $\mathrm{Su}(\mathrm{H})$ for nuclear import [28-30]. Nevertheless, as consequence of its nuclear export signal, it may also be involved in the shuttling of $\mathrm{Su}(\mathrm{H})$ protein between the nuclear and cytosolic compartments [29]. $\mathrm{Su}(\mathrm{H})$ protein not only relies on its co-factors ICN or Hairless for nuclear import. Moreover, its stability depends on complex formation, as in the absence of Hairless or Notch, $\mathrm{Su}(\mathrm{H})$ protein is considerably less abundant than in the wild-type [4]. Based on the crystal structure of the $\mathrm{Su}(\mathrm{H})-\mathrm{H}$ repressor complex, three Leucine residues specific for $\mathrm{H}$-binding were replaced by Alanine in $\mathrm{Su}(\mathrm{H})^{\mathrm{LLL}}$, which consequently lead to a loss of Hairless binding [27]. Accordingly, $\mathrm{Su}(\mathrm{H})^{\mathrm{LLL}}$ protein is barely detectable in the Drosophila tissue due to its inability to form a complex with $\mathrm{H}$ protein, indicating instability of the mutant protein [4].

Notch signaling activity is highly dose-sensitive: mutations in several Notch signaling components are haplo-insufficient, exhibiting a dominant phenotype, thereby facilitating genetic interaction studies [31-33]. For example, the Notch mutant wing phenotype is almost normalized by a second site mutation in the Hairless locus, implying that the ratio of activator to repressor should be ideally one to one $[31,33,34]$. Therefore, the question arose what happened if Hairless was unable to enter the nucleus. To achieve this scenario, a transmembrane domain was fused to Hairless in order to anchor Hairless protein at membranes, ideally confining it in the cytosol. Based on the hypothesis that Hairless binds $\mathrm{Su}(\mathrm{H})$ in the cytosol for nuclear import, in this experimental setting, $\mathrm{Su}(\mathrm{H})$ should be likewise trapped, thereby preventing the formation of repressor as well as activator complexes. The phenotypic consequences observed in the experiments support this working hypothesis.

\section{Materials and Methods}

\subsection{Cloning of the Hairless Transmembrane Coding Sequence}

The signal peptide (SP) and the transmembrane domain (TM) were derived from Delta (complete Delta cDNA in pIZ V5-His expression vector, provided by Delidakis [35]); the cloning strategy is depicted in Figure S1. The fragment coding for the signal peptide (M1 to T125) was excised by an Eco $\mathrm{RI} / \mathrm{Kpn}$ I digest and subcloned into likewise digested pUASTattB vector [36] generating pUAST SP. The sequence coding for the transmembrane domain was PCR-amplified with upper primer $5^{\prime}$ GCG AGA GCC GAT GGT ACC ACC AAT 3' with Kpn I site and lower primer 5' CCC ACT GCC ATT GTG AAA GCT TGT G $3^{\prime}$ with Hind III site (codons T591 to T646). The Kpn I/Hind III digested PCR product was cloned into likewise digested pBT (Stratagene, La Jolla, CA, USA) generating pBT TM. Into the Hairless cDNA clone [33], an additional Sal I site was introduced at position of the stop codon via site 
directed mutagenesis using primer pair Up 5 $5^{\prime}$ GAA TCT GTC AAA GCA CGT CGA CAT ACA CAC GCC $3^{\prime}$ and Low 5' GGC GTG TGT ATG TCG ACG TGC TTT GAC AGA TTC 3'. In this Sal I site and the adjacent polylinker Hind III site, a Myc-tag plus stop codon derived from pESC-LEU yeast vector (Stratagene, La Jolla, CA, USA), was cloned to generate pBT Hairless-myc. Subsequently, a Hind III digest released a Hairless fragment including codon position S212 to the C-terminal Myc-tag and stop codon, subcloned into pBT TM to generate pBT TM H. TM H was released with Kpn I and Xba I and inserted into the likewise digested pUAST SP construct to obtain the final Delta SPTM-Hairless Myc $\left(\mathrm{SPTM}-\mathrm{H}^{\mathrm{myc}}\right.$ ) pUAST attB transformation vector. The Hairless ${ }^{\text {myc }}$ cDNA and Hairless cDNA [26] were likewise cloned in pUAST attB and transgenic lines established for control expression.

\subsection{Cloning of the GFP Transmembrane Coding Sequence}

The GFP coding DNA fragment was derived from pEGEF-N1 vector (Clontech, Palo Alto, CA, USA) and cloned with Sac I/Not I into pBT vector (Stratagene, La Jolla, CA, USA). To secure the open reading frame with transmembrane sequence, GFP was excised with Bam $\mathrm{HI} / \mathrm{Xba}$ I and recloned into Bam HI/Xba I digested pBT. This step was necessary to omit polylinker sequences of pEGEF-N1 vector and to inverse the orientation. This allowed the subsequent release of a Hind III/Xba I fragment for cloning in frame with pBT TM. Subsequently, a Kpn I/Xba I fragment was inserted into likewise opened pUAST SP to obtain the Delta SPTM-GFP pUAST attB transformation vector.

\subsection{In Vivo Analysis}

The pUAST attB constructs were all integrated at chromosomal position 68E using the PhiC31 integration system as described before [26,36]. Several strains were obtained for each construct that all behaved similarly. Tissue specific expression was induced with the Gal4/UAS system [37]. For driver lines, omb-Gal4 recombined with $v g^{\mathrm{BE}}-\mathrm{lacZ}$ [38], Bx-Gal4 (also named MS1096-Gal4), pnr-Gal4, and sd-Gal4 were used (http://flybase.org). pUAST attB SPTM-H ${ }^{\text {myc }}$ at position 68E was recombined with $\mathrm{pUAST}$ attB $\mathrm{Su}(\mathrm{H})$ and $\mathrm{Su}(\mathrm{H})^{\mathrm{LLL}}$ constructs, respectively, located at chromosomal position 96E $[4,27]$ to allow for co-overexpression. LacZ expression was detected by antibody staining using anti $\beta$-galactosidase (1:250) (clone 40-1a; developed by J.R. Sanes; obtained by Developmental Studies Hybridoma Bank, University of Iowa, IA, USA). Hairless was detected either with anti H antibodies from guinea pig (1:500) [39] or with anti-Myc-tag antibodies A4-1 from rabbit (1:1000) (Santa Cruz Biotechnology, Santa Cruz, CA, USA), to specifically detect transgene expression. Su(H) was detected with antibodies generated in rabbit (1:500) (Santa Cruz Biotech, Dallas, TX, USA) or rat [39]. For the detection of Lamin C (1:20) (LC28.26), Wingless (1:25) (4D4), Cut (1:25) (2B10), and $\beta$-galactosidase (1:250) (40-1a) mouse monoclonal antibodies were applied (developed by P.A. Fisher, S.M. Cohen, G.M. Rubin and J.R. Sanes, respectively; obtained by Development Studies Hybridoma Bank, University of Iowa, IA, USA). GFP was detected with rabbit anti-GFP (1:250) (Santa Cruz Biotech, Dallas, TX, USA) and Putzig with guinea pig anti-Pzg (1:1000) [40]. To outline cell membranes, filamentous actin was labeled with Rhodamine-coupled phalloidin (1:200; Molecular Probes, Eugene, OR, USA). The Golgi compartment was marked with mouse antibodies against the human p230 trans-Golgi (1:500) (clone 15; BD Biosciences, San Jose, CA, USA) and goat antibodies against Drosophila Gmap cis-Golgi (1:1000) [41]. Secondary antibodies coupled with FITC, Cy3, and Cy5 (all 1:200) were purchased from Jackson Immuno-Research Laboratories (Dianova, Hamburg, Germany). Fluorescently labelled tissue was prepared as described earlier and mounted in Vectashield (Vector labs, Eching, Germany). Pictures were taken with a confocal microscope (BioRad, MRC 1024, Munich, Germany) linked to a Zeiss Axioskop using LaserSharp 2000TM software (Zeiss, Jena, Germany). Adult wings were dehydrated in ethanol, mounted in Euparal (Roth, Karlsruhe, Germany) and documented with an ES 120 camera (Optronics) linked to a Zeiss Axiophot (Zeiss, Jena, Germany), using Pixera Viewfinder Pro2.5 software (Pixera, Santa Clara, CA, USA). Adult flies were etherized and pictured with a table top scanning electron microscope JCM-5000 SEM (Nikon, Tokyo, Japan). Pictures were assembled using Image J (open source), Photo Paint, and Corel Draw software (Corel, Ottawa, Canada). 


\subsection{Western Blotting}

pUAST attB SPTM- $\mathrm{H}^{\mathrm{myc}}$ and $\mathrm{H}^{\mathrm{myc}}$ flies were crossed to $d a-G a l 4$ for ubiquitous expression. Embryos were collected overnight at room temperature on apple juice plates, and dechorionated in $50 \%$ sodium hypochlorite bleach. Two hundred embryos each were homogenized on ice in $50 \mu \mathrm{L}$ RIPA I buffer $(300 \mathrm{mM} \mathrm{NaCl}, 100 \mathrm{mM}$ Tris- $\mathrm{HCl} \mathrm{pH}$ 7.5, plus one tablet Roche complete ULTRA protease inhibitor). After centrifugation, loading buffer was added to the supernatant, which was boiled before separation by SDS-PAGE, followed by Western blotting. Hairless was detected either with anti-H antibodies from guinea pig (1:500) [39] or with anti-Myc tag antibodies A4-1 from rabbit (1:1000) (Santa Cruz Biotechnology, Santa Cruz, CA, USA). Anti-rabbit or anti-mouse secondary antibodies from guinea pig coupled with alkaline phosphatase were used for detection (Jackson Immuno-Research, obtained from Dianova, Hamburg, Germany).

\subsection{Statistical Evaluation}

Area of female wings was determined using the freehand tool of Image J (open source). Bristles were counted in a determined area on female thoraces. Statistical analysis was conducted by Student's $t$ test: ${ }^{* * *} p<0.001$ highly significant; ${ }^{* *} p<0.01$ very significant; ${ }^{*} p<0.05$ significant; not significant (ns) $p>0.05$. Graphs were compiled with Origin ${ }^{\circledR} 2018 \mathrm{~b}$ software from Origin lab (Northampton, MA, USA).

\section{Results}

\subsection{Cloning Strategy}

The aim of the cloning strategy was to obtain a cDNA coding for Hairless coupled N-terminally to a transmembrane domain as well a signal peptide necessary for integration into plasma membranes. Moreover, the Hairless protein should be in the cytosolic compartment.

Hairless possesses an internal ribosomal entry site (IRES) within the coding region, which leads to two main Hairless protein isoforms starting with the second and third Methionine, M2 and M3, respectively (Figure S1) [42,43]. Both isoforms contain all known functional Hairless domains: Suppressor of Hairless binding domain (SBD), Groucho binding domain (GBD), and C-terminal protein binding domain (CBD) [23-25], as well as the known nuclear import and export signals [29]. To avoid translation of a Hairless protein isoform without transmembrane domain by internal ribosomal entry, only the Hairless portion downstream of the IRES was fused with the transmembrane domain (Figure 1a and Figure S1).

For the transmembrane domain and the signal peptide, I choose that of Delta and not of Notch to avoid intra-membrane cleavage [35]. Cloning details are outlined in Figure S1: apart from the Delta transmembrane domain, which was obtained by PCR amplification including relevant restriction sites, it was possible to clone the construct using internal restriction sites. The resultant construct has an open reading frame starting $5^{\prime}$ with the signal peptide followed by sequences for the transmembrane domain and ending $3^{\prime}$ with a Myc-tag added to the Hairless coding sequences (Figure 1a and Figure S1a). To generate an appropriate control, GFP was fused in a similar way with the Delta transmembrane domain and signal peptide. The final constructs were sequence-verified. Both peptides are predicted transmembrane proteins with the major body in the cytosol by the combined transmembrane topology and signal peptide predictor Phobius [44] (Figure 1b). Using the pUAST attB vector, they were each inserted at position 68E with the PhiC31 integration system [36], generating UAS-SPTM- $\mathrm{H}^{\text {myc }}$ and UAS-SPTM-GFP, respectively. Protein sequences are shown in Figure S2. In vivo expression of SPTM- $\mathrm{H}^{\text {myc }}$ protein was verified in Western blots. To this end, ubiquitous protein expression was induced in embryos by crossing UAS-SPTM- ${ }^{\text {myc }}$ with $d a$-Gal4 (Figure S1b,c). 
a

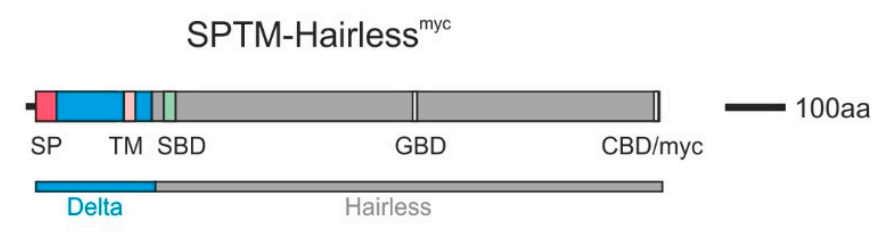

b

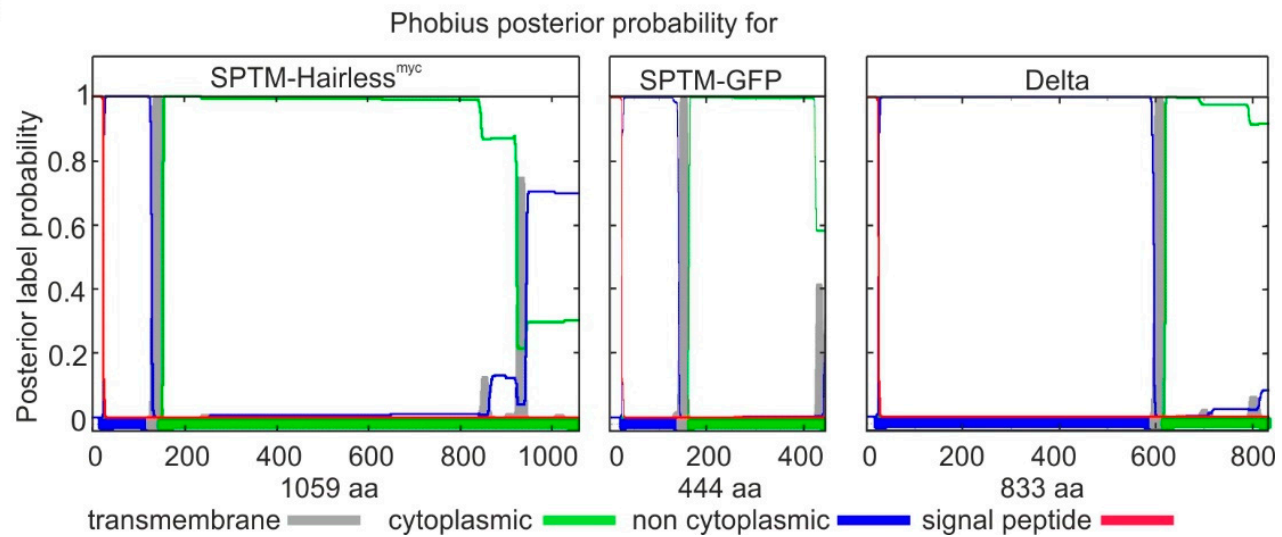

Figure 1. Construction of a membrane-anchored Hairless isoform. (a) Scheme of the SPTM-Hyc transgene. Delta protein (blue) containing the signal peptide (SP, magenta) and the transmembrane domain (TM, pink) was fused to Hairless protein (grey) containing the $\mathrm{Su}(\mathrm{H})$ binding domain (SBD, green), the Groucho binding domain (GBD), the binding domain for the C-terminal binding protein (CBD), as well as a C-terminal Myc-tag (myc). Scale corresponds to 100 amino acids (aa). This SPTM-H $\mathrm{H}^{\text {my }}$ construct was cloned into $\mathrm{pUAST}$ attB vector to be integrated at position $68 \mathrm{E}$ in the fly genome; (b) Plots showing predicted transmembrane domain and signal peptides established with the phobius database (http://phobius.sbc.su.se). The posterior label probability of signal peptide (red) and transmembrane (grey) is shown on the $y$-axis $(1=100 \%$ probability). The $x$-axis represents the amino acids of the evaluated protein as well as the probability of the subcellular localization (green = cytoplasmic orientation.

\subsection{In Vivo Consequences of the Overexpression of SPTM- $H^{m y c}$ Protein}

\subsubsection{Subcellular Localization of Overexpressed SPTM- $\mathrm{H}^{\text {myc }}$ Protein in Salivary Glands}

The cells are very small in Drosophila larval tissue, which makes it difficult to detect the subcellular localization of proteins, especially if expected in the cell membrane. Therefore, expression of SPTM-H $\mathrm{H}^{\mathrm{myc}}$ was first induced in salivary glands of third instar larvae that contain giant cells and nuclei, using the driver line $s d$-Gal4. Since endogenous Hairless protein is primarily detected in the nucleus (Figure 2a) [28-30], the nuclear protein Putzig (Pzg) was used as a marker [40]. As expected, the overexpressed SPTM-GFP control protein was not nuclear but mainly associated with the cell membrane, however, was also seen in a meshwork throughout the cytosol (Figure 2b). In contrast to the wild-type Hairless protein, SPTM-H ${ }^{\text {myc }}$ was absent from salivary gland nuclei (Figure 2c). The most prominent staining was observed at the nuclear envelope (Figure 2c-e).

To confirm the expected membrane staining, cells were outlined by visualizing filamentous actin with phalloidin (Figure 2d). Again, the most prominent staining for SPTM-H ${ }^{\text {myc }}$ was at the nuclear envelope; however, it was also seen at the outer cell membrane. Staining of the plasma membrane seemed obscured by glue protein vesicles, and appears in a different focal plane than the nuclear envelope (Figure 2d) [45,46]. A co-staining with two different Golgi markers conforms to SPTM-H ${ }^{\text {myc }}$ present in the Golgi compartment as well as close to the endoplasmic reticulum (ER) (Figure 2e,f). 

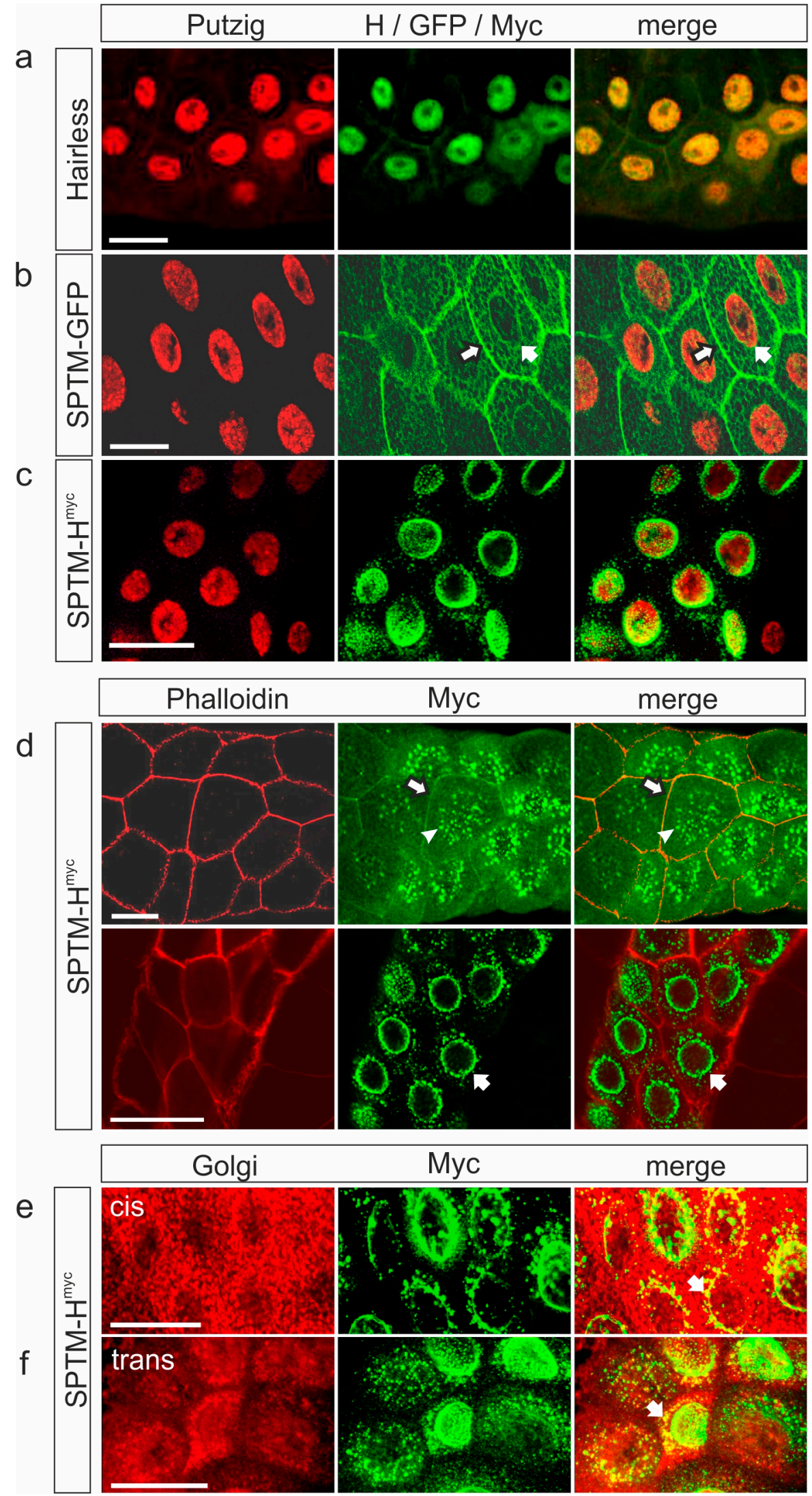

Figure 2. Subcellular localization of the given fusion proteins. Salivary glands from third instar larvae; expression of the given constructs was induced with $s d-G a l 4$ and detected with respective antibodies against H (a), GFP (b), and Myc (c), labelled in green. Nuclei were marked with anti-Putzig (a-c); cell 
outlines with Rhodamin-coupled Phalloidin (d), cis-Golgi with anti-Gmap (e), and trans-Golgi with anti-p230 (f), labelled in red. Size bars represent $50 \mu \mathrm{m}$. (a) Wild-type H strongly accumulated in the nucleus; (b) SPTM-GFP protein was associated with the cell membrane (black-framed arrow) and the nuclear envelope (arrow); (c) No co-localization of SPTM- $\mathrm{H}^{\text {myc }}$ and Putzig is seen; instead, SPTM-H ${ }^{\text {myc }}$ is highly enriched at the nuclear envelope; (d) Upper panel: SPTM-H ${ }^{\text {myc }}$ protein is visible in a more punctuated pattern in the proximal part of the gland (example marked with arrowhead) and is detected also at the outer cell membrane (black-framed white arrow). Lower panel: a prominent staining at the nuclear envelope encircled by a corona of apparent vesicles (arrow) is present in a more proximal part frequently seen in same gland; (e,f) Co-localization of SPTM- $\mathrm{H}^{\mathrm{myc}}$ protein (green) with the cis-Golgi marker Gmap (red) (e) and the trans-Golgi marker p230 (red) (f) is seen (overlap appears yellow in the merge, arrow).

Next, a double staining of SPTM- $\mathrm{H}^{\text {myc }}$ with endogenous $\mathrm{Su}(\mathrm{H})$ was performed. Endogenous $\mathrm{Su}(\mathrm{H})$ is expected to accumulate in the nucleus (Figure 3a) [47]. If $\mathrm{Su}(\mathrm{H})$ is trapped by SPTM-H ${ }^{\mathrm{myc}}$, a co-localization of both proteins is expected: in fact, co-staining was detected in the Golgi compartment, and along the plasma membrane to a lower extent (Figure 3b). However, a considerable portion of endogenous $\mathrm{Su}(\mathrm{H})$ protein was present in the nucleus, indicating incomplete anchoring by SPTM-H ${ }^{\text {myc }}$.

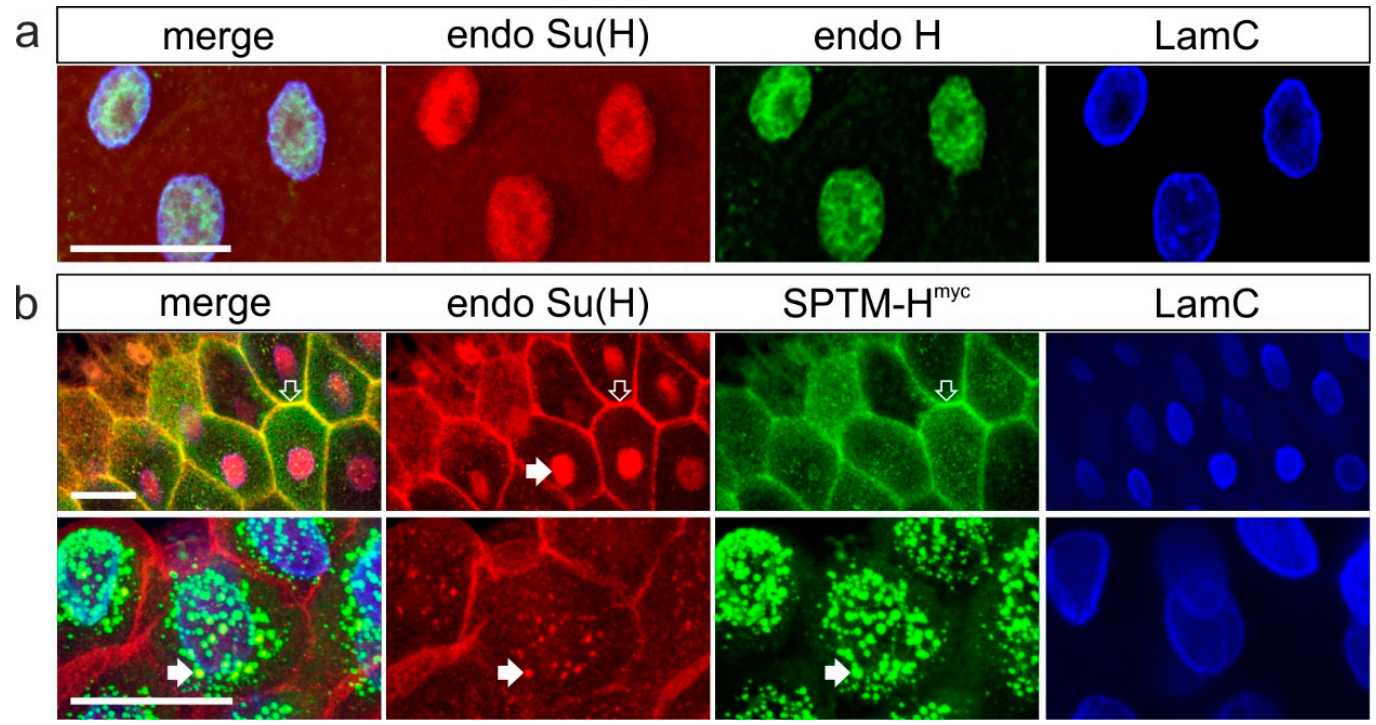

Figure 3. $\mathrm{Su}(\mathrm{H})$ protein co-localizes with $\mathrm{SPTM}-\mathrm{H}^{\mathrm{myc}}$ in salivary glands. (a) Endogenous expression of Hairless $(\mathrm{H}$, green) and $\mathrm{Su}(\mathrm{H})($ red) in salivary glands. Both proteins accumulate in the nucleus. The nuclear envelope is marked with Lamin C (LamC, blue); (b) co-localization of endogenous $\mathrm{Su}(\mathrm{H})$ (red) with ectopically expressed SPTM-H ${ }^{\text {myc }}$ protein (green). Upper panel: mostly localized in the nucleus (arrow), endogenous $\mathrm{Su}(\mathrm{H})$ is also present along the outer plasma membrane just like SPTM-H ${ }^{\text {myc }}$ (open arrows). Lower panel: a different focal plane reveals co-localization of endogenous $\mathrm{Su}(\mathrm{H})$ and SPTM- $\mathrm{H}^{\mathrm{myc}}$ also along the nuclear periphery within the presumptive Golgi compartment (arrow) in a more distal portion of the salivary gland. Size bars represent $50 \mu \mathrm{m}$.

\subsubsection{Phenotypic Consequences Resulting from SPTM- $\mathrm{H}^{\text {myc }}$ Overexpression}

Next, the consequences on fly development were addressed: using the $B x$-Gal4 driver line, UAS-SPTM-H ${ }^{\text {myc }}$ line was overexpressed in the anlagen of the meta-thorax and the wings [48]. Both tissues are known to be highly susceptible to a change in Notch signaling activity. In contrast to the SPTM-GFP control, SPTM-H ${ }^{\text {myc }}$ affected the development of mechano-sensory bristles on the thorax as well as the development of the wing at $29^{\circ} \mathrm{C}$ (Figure 4). Notably, the number of microchaetae was elevated, which is a typical sign of reduced Notch activity (Figure $4 a, c)$ [31,34]. For a quantification of bristle numbers, pictures of thoraces were taken by scanning electron microscopy, and the microchaetae were counted within a square 
between the intrascutal suture and the posterior dorsocentral macrochaetae in two independent experiments (Figure 4a). Whereas control flies displayed an average of about 55 microchaetae, flies overexpressing SPTM-H ${ }^{\text {myc }}$ featured 75 microchaetae on average (Figure 4a,c). This is a highly significant increase in bristle number of almost $37 \%$. In addition, the wings of flies overexpressing SPTM- $\mathrm{H}^{\text {myc }}$ appeared smaller compared to control, and frequently contained additional wing vein material (Figure $4 b$ ). A quantification of wing size revealed a highly significant reduction of about $13 \%$ due to $\mathrm{SPTM}-\mathrm{H}^{\text {myc }}$ overexpression (Figure 4c). As Notch activity regulates growth, this phenotype conforms to reduced Notch activity [49-51]. In sum, excessive SPTM- $\mathrm{H}^{\text {myc }}$ protein interferes with Notch activity, presumably by sequestering $\mathrm{Su}(\mathrm{H})$ protein within the cytoplasm by its membrane-anchor (Figure 3b), thereby limiting its availability for ICN, and hence for activator-complex assembly.

a
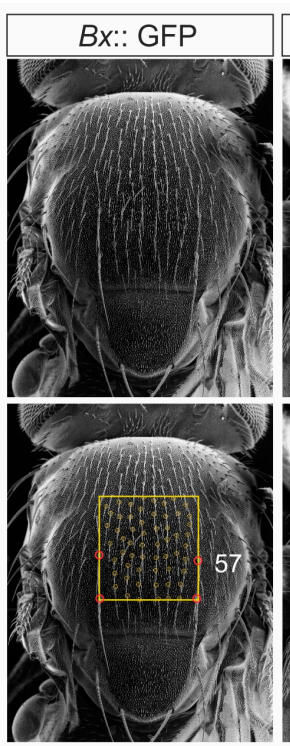

$B x::$ SPTM- $\mathrm{H}^{\mathrm{mic}}$
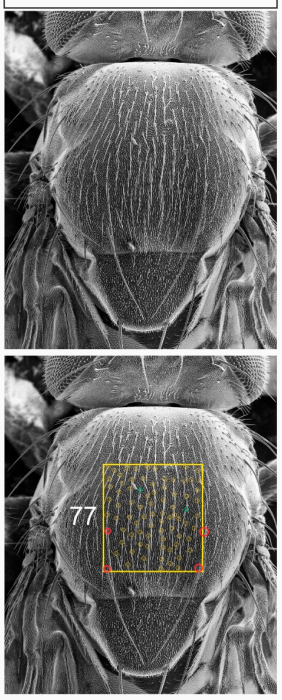

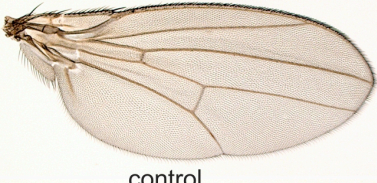

control

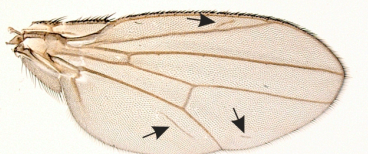

SPTM $\mathrm{H}^{\text {myc }}$

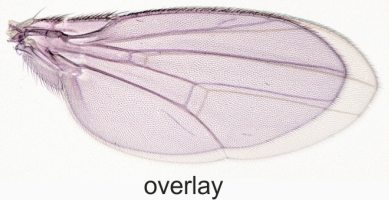

C
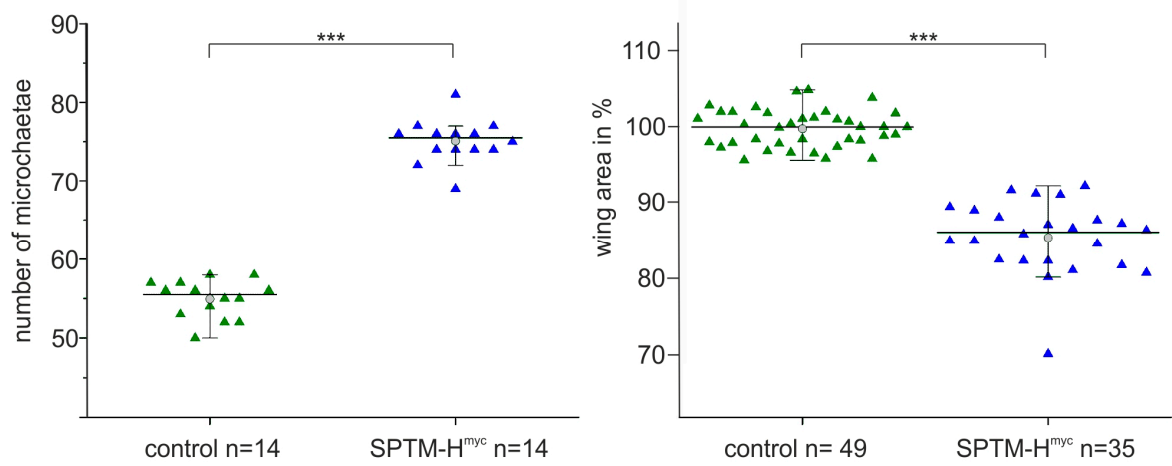

Figure 4. Consequences of SPTM- $\mathrm{H}^{\mathrm{myc}}$ on adult development. Phenotypic analysis of adult flies upon SPTM- $\mathrm{H}^{\text {myc }}$ overexpression with $B x$-Gal4 at $29^{\circ} \mathrm{C}$. $B x$-Gal4 drives expression in the anlagen of wing and thorax [48]. (a) Scanning electron micrographs show thoraces of flies; GFP for control and SPTM-H ${ }^{\text {myc }}$, respectively, were overexpressed during development. Below, the same images illustrating data analysis: the area of bristle counts is outlined and the counted microchaetae are encircled in yellow (GFP 57, SPTM-H ${ }^{\text {myc }}$ 77 microchaetae). Red circles mark the anterior and posterior dorsocentral macrochaetae; (b) Wings of female flies overexpressing GFP (control) and SPTM- $\mathrm{H}^{\mathrm{myc}}$, respectively. Note additional wing veins (arrow) and smaller wing size in the mutant. The latter is clearly seen in the overlay (GFP is shown in grey, SPTM- $\mathrm{H}^{\mathrm{myc}}$ is colored in purple); (c) statistical graphs depicting total microchaetae counts (left panel) and wing area in \% of control (right panel). Circle, mean value; horizontal bar, median; error bars, standard deviation. Sample size is given below (n). The differences between GFP control and SPTM- $\mathrm{H}^{\text {myc }}$ are highly significant $\left(p<0.001^{* * *}\right)$ by Student's $t$-test. 


\subsubsection{Influence of SPTM- $\mathrm{H}^{\text {myc }}$ on the Activity of Notch Target Genes in Wing Imaginal Discs}

If the above assumption were correct, an interference of excessive SPTM- $\mathrm{H}^{\text {myc }}$ protein with Notch target gene activity would be expected. To address this idea, SPTM- $\mathrm{H}^{\text {myc }}$ was overexpressed just in the center of wing imaginal discs using the $o m b$-Gal4 driver line, to allow for a comparison with adjacent wild-type cells. UAS-SPTM-GFP served as control. The following Notch targets were investigated: vestigial (using the vestigial boundary enhancer coupled to a Lac-Z reporter gene, $v g^{B E}$-lacZ) [38] (Figure 5a-c), Wingless (Figure 5d), and Cut (Figure 5e). Overexpression of SPTM- $\mathrm{H}^{\text {myc }}$ did not alter the expression of the Notch target genes in the omb domain, in contrast to the effects of an overexpression of wild-type $\mathrm{H}$ (compare Figure 5 a with Figure $5 \mathrm{c}-\mathrm{e}$ ), but rather resembled the expression of the GFP control (compare Figure 5b with Figure $5 c$ ). Whereas excessive $\mathrm{H}$ resulted in the expected loss of $v g^{B E}-$ lacZ reporter gene expression along the dorso-ventral boundary (Figure 5a) [26,52], SPTM- $\mathrm{H}^{\text {myc }}$ did not effect a similar loss, and the discs matched control (Figure $5 b, c)$. Likewise, no effect on the expression of Wingless (Figure 5d) nor of Cut (Figure 5e) was observed. These results demonstrate that SPTM- $\mathrm{H}^{\text {myc }}$ cannot silence Notch target gene activity to a similar degree as the wild-type $\mathrm{H}$ protein in wing imaginal discs (Figure 5). However, SPTM- $\mathrm{H}^{\text {myc }}$ may ameliorate Notch activity as reflected by the defects seen in the adult flies (Figure 4). Presumably, ICN's affinity to $\mathrm{Su}(\mathrm{H})$ is high enough to recruit adequate amounts for activator complex assembly to induce target gene expression. This may be even in exchange for binding to Hairless, since ICN is able to outcompete Hairless in vitro [26].

A detailed analysis of the samples at high magnification, however, confirmed the results from the salivary glands with a primary expression of SPTM- $\mathrm{H}^{\text {myc }}$ protein along the nuclear envelope (see enlargements in Figure $5 \mathrm{a}^{\prime}-\mathrm{e}^{\prime}$ ). SPTM- $\mathrm{H}^{\text {myc }}$ protein accumulated in a punctuated pattern (or vesicles) within the $o m b$ expression domain (Figure $5 c^{\prime}-\mathrm{e}^{\prime}$ ), a pattern clearly different from the ectopic expression of a wild-type Hairless protein, which is enriched in the nucleus (Figure $5 a^{\prime}$ ). In single confocal sections, SPTM- $\mathrm{H}^{\text {myc }}$ protein was detected in circles, similar to SPTM-GFP (Figure $5 b^{\prime}, \mathrm{c}^{\prime}$ ). In stacked images, SPTM-H protein appeared as dots (Figure $5 \mathrm{~d}^{\prime}, \mathrm{e}^{\prime}$ ), encircling the nucleus compared to the nuclear protein Cut, presumably corresponding to the ER (Figure $5 \mathrm{e}^{\prime}$, small arrow), whereas the larger dots may correspond to the Golgi compartment (Figure $5 \mathrm{~d}^{\prime}, \mathrm{e}^{\prime}$, open arrow). A co-staining with the nuclear marker Pzg showed little or no overlap of the dots with the nuclei; an apparent overlay is a result of the summary of the stacks (Figure 5d'). Using cytoplasmic Wingless expression as an additional marker, a clearly separate staining from the Pzg nuclear expression was noted (Figure 5d', arrow), however, a frequent overlap with SPTM- $\mathrm{H}^{\text {myc }}$ was seen as yellow mix color (Figure $5 \mathrm{~d}^{\prime}$, open arrow).

\subsection{Effects of a Combined Overexpression of SPTM- $H^{m y c}$ and $S u(H)$}

In the next series of experiments, UAS-SPTM- $\mathrm{H}^{\text {myc }}$ was overexpressed in combination with $\mathrm{Su}(\mathrm{H})$. Several questions were addressed: firstly, is $\mathrm{Su}(\mathrm{H})$ co-localized with SPTM- $\mathrm{H}^{\text {myc }}$ as predicted? Secondly, what are the effects on Notch target gene expression? Thirdly, what are the phenotypic consequences on fly development? Finally, the consequences of a combination with the $\mathrm{Su}(\mathrm{H})^{\mathrm{LLL}}$ mutation deficient for Hairless-binding was investigated in comparison to the wild-type $\mathrm{Su}(\mathrm{H})[4,27]$. Here, the expectation was that SPTM- $\mathrm{H}^{\text {myc }}$ should not affect $\mathrm{Su}(\mathrm{H})^{\mathrm{LLL}}$ activity due to a lack of binding.

\subsubsection{Co-localization of $\mathrm{SPTM}-\mathrm{H}^{\mathrm{myc}}$ and $\mathrm{Su}(\mathrm{H})$ in Salivary Glands}

As shown earlier, $\mathrm{Su}(\mathrm{H})$ relies on Hairless for nuclear entry, closely following $\mathrm{H}$ protein distribution in wild-type and experimental settings [28,29]. Therefore, in co-overexpression experiments of wild-type Hairless with $\mathrm{Su}(\mathrm{H})$, both proteins are almost completely nuclear (Figure 6a). Co-localization studies were performed in salivary glands of third instar larvae to take advantage of the huge size of the polytene cells. To this end, the transgenes UAS-SPTM- $\mathrm{H}^{\text {myc }}$ and UAS-Su(H) were recombined to be jointly overexpressed in salivary glands using $s d$-Gal4. A large, albeit not complete overlap of $\mathrm{Su}(\mathrm{H})$ and SPTM- $\mathrm{H}^{\text {myc }}$ proteins was noted (Figure 6b). Notably, there was a clear overlap in the punctuated staining along the nuclear envelope, presumably corresponding to the ER and Golgi compartment 
(Figure 6b, arrow). Curiously, $\mathrm{Su}(\mathrm{H})$ was virtually absent from the nucleus (Figure 6b, open arrow). In addition, a weak cytoplasmic staining was detected overall, presumably corresponding to free $\mathrm{Su}(\mathrm{H})$ not anchored by SPTM-H ${ }^{\text {myc }}$. In this experiment, SPTM- $\mathrm{H}^{\text {myc }}$ was detected with anti-Myc antibodies to display expression of the SPTM-H ${ }^{\text {myc }}$ transgene only, and not be confused by wild-type H protein.

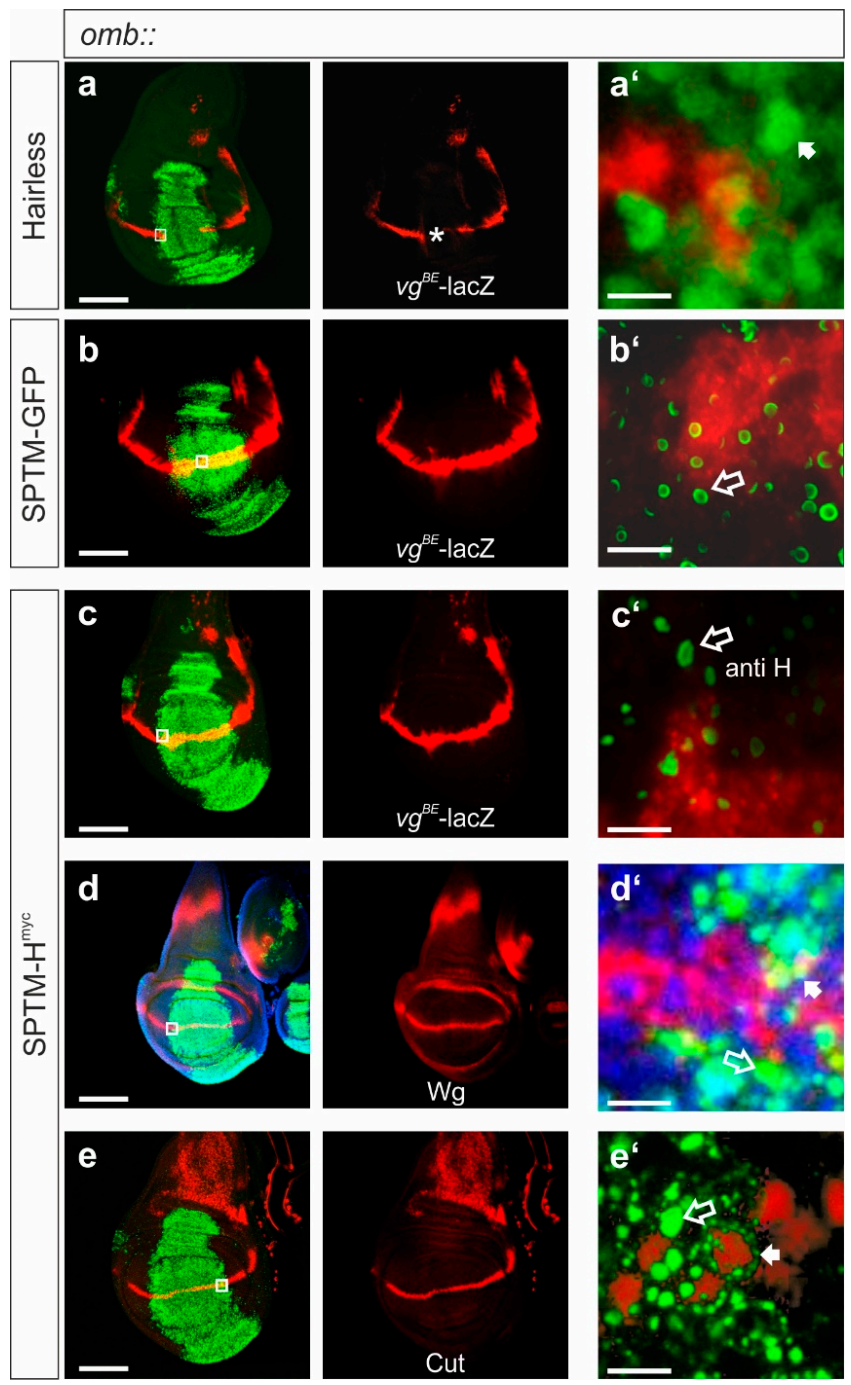

Figure 5. Effects of SPTM-H $\mathrm{H}^{\text {myc }}$ overexpression on Notch target genes. Ectopic expression of the respective constructs was induced with $o m b$-Gal4 in wing imaginal discs. (a) Expression of wild-type Hairless protein; (b) of SPTM-GFP, (c-e) and of SPTM-H $\mathrm{H}^{\text {myc }}$ is shown in green. Expression of Notch targets, (a-c) the $v g^{B E}$-lacZ reporter, (d) Wingless (Wg), and (e) Cut is shown in red. (d) Nuclei are marked in blue by anti-Pzg staining. ( $\left.\mathbf{a}^{\prime}-\mathbf{e}^{\prime}\right)$ Large magnifications and selected stacks are shown. The area of the enlargements is depicted as the white square in (a-e). Size bars represent $100 \mu \mathrm{m}$ in $(\mathbf{a}-\mathbf{e})$, and $5 \mu \mathrm{m}$ in $\left(\mathbf{a}^{\prime}-\mathbf{e}^{\prime}\right)$. (a) Whereas ectopic $\mathrm{H}$ repressed the $v g^{B E}$-lacZ reporter along the dorso-ventral border (asterisk), SPTM-H ${ }^{\text {myc }}$ did not; compare (c) with control in (b). Moreover, little influence was noticed on Notch targets Wg or Cut (d,e). ( $\left.\mathbf{a}^{\prime}\right)$ Note nuclear staining of H (arrow). $\left(\mathbf{b}^{\prime}\right)$ Membrane-anchored SPTM-GFP, $\left(\mathbf{c}^{\prime}-\mathbf{e}^{\prime}\right)$ and SPTM-H ${ }^{\text {myc }}$ proteins instead appear in a punctuated pattern, sometimes in circle-like vesicles $\left(\mathbf{b}^{\prime}, \mathbf{c}^{\prime}\right.$; open arrow). These larger vesicles are separate from the nuclear envelope, which is obvious in the double staining of SPTM- $\mathrm{H}^{\mathrm{myc}}$ with the nuclear protein Cut (red in $\left.\mathbf{e}^{\prime}\right)$. Compare also with enlargement in ( $\mathbf{d}^{\prime}$, open arrow); Pzg staining served as nuclear marker (blue). The small arrow points to smaller dots in the nuclear periphery presumably corresponding to the ER $\left(\mathbf{d}^{\prime}, \mathbf{e}^{\prime}\right)$. This is quite apparent in $\left(\mathbf{e}^{\prime}\right)$, where the small dots of SPTM-H $\mathrm{H}^{\mathrm{myc}}$ fully encircle the nucleus (small arrow). 


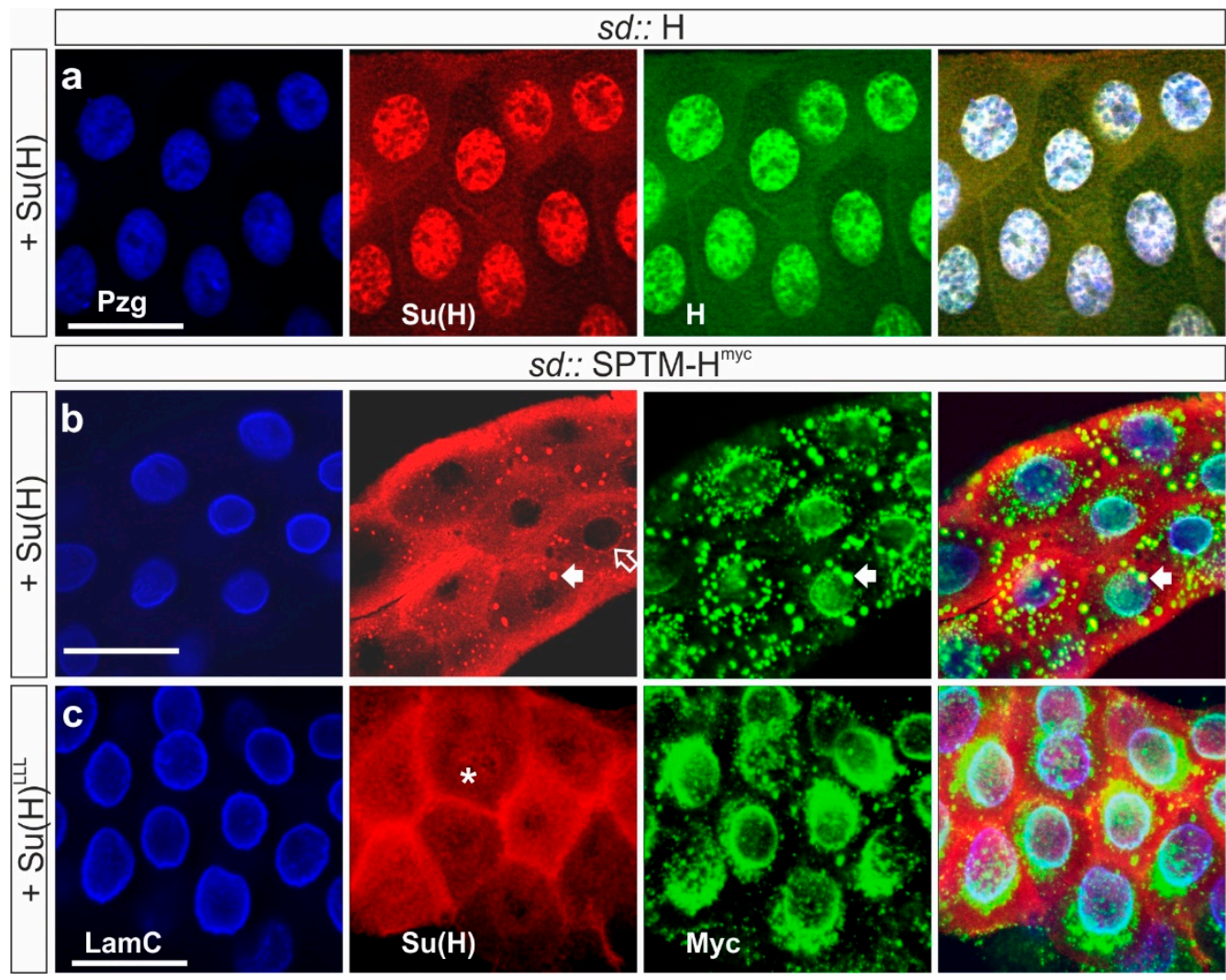

Figure 6. Combined overexpression of $\mathrm{SPTM}-\mathrm{H}^{\mathrm{myc}}$ with $\mathrm{Su}(\mathrm{H})$ in salivary glands. Ectopic expression of the given UAS constructs was induced in salivary glands using $s d$-Gal4. The nucleus is marked in blue with Putzig (Pzg) (a), and the nuclear envelope with Lamin C (LamC) in (b,c). Hairless is shown in red and $\mathrm{Su}(\mathrm{H})$ in green. The size bars represent $50 \mu \mathrm{m}$. (a) Note very strong nuclear accumulation of both wild-type Hairless and $\mathrm{Su}(\mathrm{H})$ proteins; (b) $\mathrm{Su}(\mathrm{H})$ co-localized with SPTM-H ${ }^{\text {myc }}$ in the presumptive Golgi (arrows). It appeared nearly absent from nuclei (open arrow); (c) H-binding defective $\mathrm{Su}(\mathrm{H})^{\mathrm{LLL}}$ mutant protein appears evenly distributed and is also detected within the nucleus (asterisk). No co-localization with SPTM-H ${ }^{\text {myc }}$ was observed.

Co-overexpression of SPTM- $\mathrm{H}^{\text {myc }}$ with $\mathrm{Su}(\mathrm{H})^{\mathrm{LLL}}$ was according the expectations: explained by the lack of binding of the two proteins, no co-localization was observed. Instead, $\mathrm{Su}(\mathrm{H})^{\mathrm{LLL}}$ protein was evenly distributed in the cytoplasm of salivary glands cells, whereas the punctuate-pattern typifying SPTM- $\mathrm{H}^{\text {myc }}$ protein was present in the nuclear periphery (Figure $6 \mathrm{c}$ ). In contrast to $\mathrm{Su}(\mathrm{H})$, the mutant $\mathrm{Su}(\mathrm{H})^{\mathrm{LLL}}$ protein was also weakly detected in the nucleus (asterisk in Figure 6c), which is attributed to Notch-mediated nuclear import [2,29].

\subsubsection{Consequences of the Co-Expression of SPTM- $\mathrm{H}^{\text {myc }}$ and $\mathrm{Su}(\mathrm{H})$ on Notch Target Gene Expression}

Notch target gene expression was analyzed in wing imaginal discs, overexpressing SPTM- $\mathrm{H}^{\mathrm{myc}}$ plus $\mathrm{Su}(\mathrm{H})$ under the control of $o m b-G a l 4$, thereby allowing a comparison of wild typical and affected tissue. Expression of $v g^{B E}$-lacZ [38] (Figure 7), of Wingless (Supplementary Figure S3), and Cut (Supplementary Figure S4) were investigated. Two opposing effects were noted. Whereas target gene expression vanished in the center of the omb expression domain, the entire domain expanded, displaying a faint overall protein expression (Figure 7b, b', Supplementary Figures S3-S5). Downregulation of Notch target gene expression is a clear result of a repression of Notch activity. Overgrowth of the expression domain, and induction of expression, however, is in contrast a sign of a gain of Notch activity. The latter may be a result of excessive $\mathrm{Su}(\mathrm{H})$ protein, since similar phenotypes were observed before with sole $\mathrm{Su}(\mathrm{H})$ overexpression [26,52]. Accordingly, no super-repression was achieved, which 
is typical of the combined overexpression of wild-type Hairless together with $\mathrm{Su}(\mathrm{H})[23,26,52,53]$. In this case, a severe tissue loss is observed because of a strong repression of Notch activity (Figure 7a).
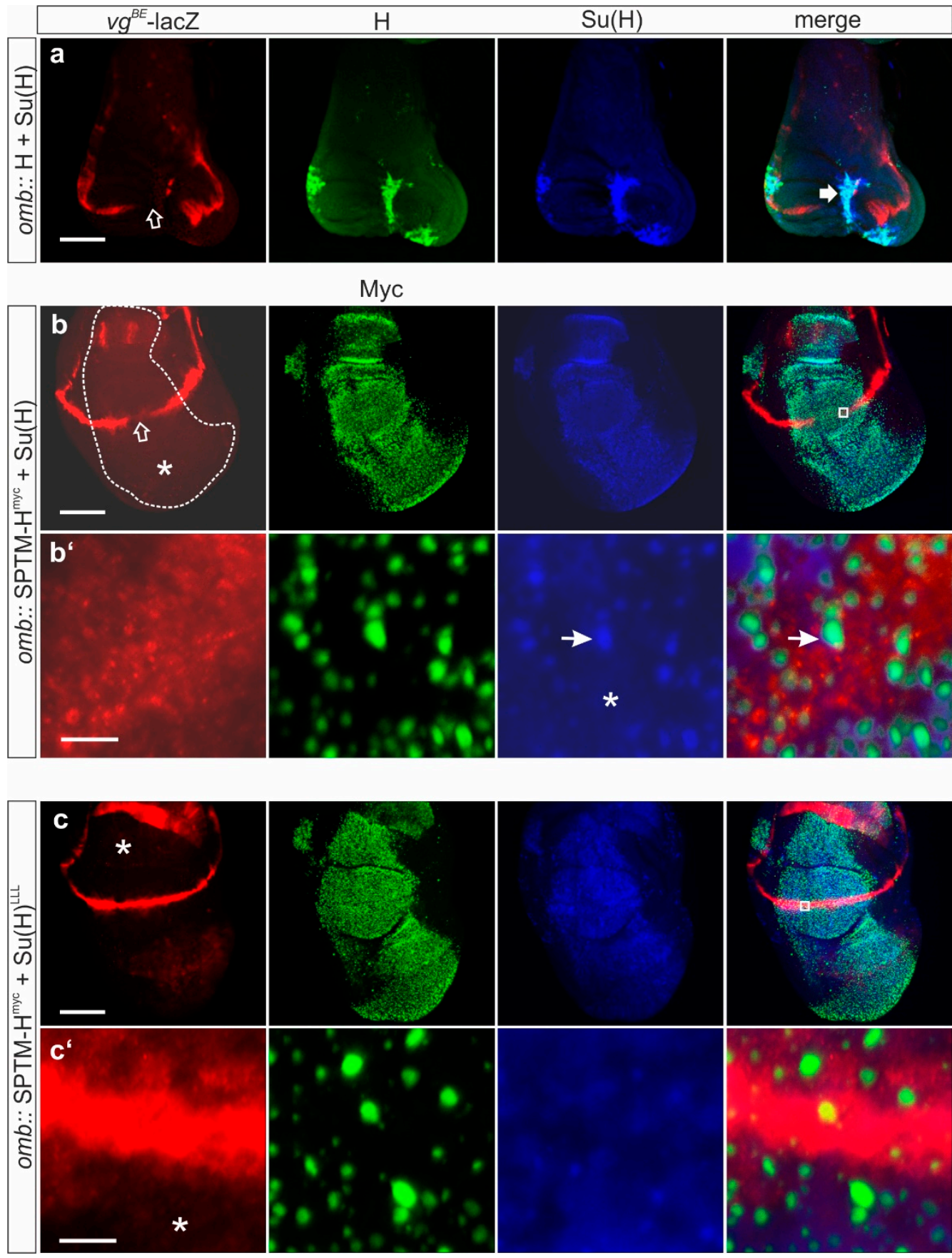

Figure 7. Influence of the combined overexpression of SPTM- $\mathrm{H}^{\mathrm{myc}}$ and $\mathrm{Su}(\mathrm{H})$ on Notch reporter gene expression. Ectopic expression of the given UAS constructs was induced in imaginal discs using $o m b$-Gal4. Expression of the $v g^{B E}$-lacZ reporter is shown in red; of Hairless in green, and of $\mathrm{Su}(\mathrm{H})$ in blue. (a) In combination, wild-type Hairless and $\mathrm{Su}(\mathrm{H})$ induce extreme repression of Notch activity, reflected by the near complete loss of tissue (thick arrow) and a strong repression of the $v g B E$-lac $Z$ reporter (open arrow); (b) The co-overexpression of SPTM- $\mathrm{H}^{\text {myc }}$ with $\mathrm{Su}(\mathrm{H})$ caused a gap in the expression of the $v g^{B E}$-lacZ reporter along the dorso-ventral boundary (open arrow). In addition, the reporter was weakly induced throughout the omb-expression domain (asterisk). Note overgrowth of the affected tissue. The $\mathrm{Su}(\mathrm{H})$ staining largely followed the SPTM-H $\mathrm{H}^{\text {myc }}$ staining $\left(\mathbf{b}^{\prime}\right.$, arrow points to one example), 
however, appears less distinct and more uniform ( $\mathbf{b}^{\prime}$, asterisk); (c) Overexpression of the H-binding defective $\mathrm{Su}(\mathrm{H})^{\mathrm{LLL}}$ mutant protein induced an even more pronounced overgrowth, however, did not induce ectopic expression of the $v g^{B E}$-lacZ reporter (asterisk), nor a repression along the boundary. Overall, $\mathrm{Su}(\mathrm{H})^{\mathrm{LLL}}$ protein was present at a remarkably low level and showed no overlap with $\operatorname{SPTM}-H^{\text {myc }}\left(\mathbf{c}^{\prime}\right)$. Size bars represent $100 \mu \mathrm{m}(\mathbf{a}-\mathbf{c})$, and $5 \mu \mathrm{m}\left(\mathbf{b}^{\prime}, \mathbf{c}^{\prime}\right)$, respectively. The area of enlargement is depicted as a white square in the merge picture of (b) and (c).

Moreover, whereas the Hairless-Su(H) repressor complex was mostly nuclear, SPTM- $\mathrm{H}^{\text {myc }}$ and $\mathrm{Su}(\mathrm{H})$ proteins were not but rather co-localized in the dotted structures described above (Figure $7 \mathrm{~b}, \mathrm{~b}^{\prime}$, Figures S3a and S4a). Accordingly, no such co-localization was observed in the combined overexpression with $\mathrm{Su}(\mathrm{H})^{\mathrm{LLL}}$ lacking the Hairless-binding site (Figure 7 and Figure S4b). Since both combined overexpression settings resulted in a similar overgrowth of the disc (Figure S5), I conclude that excess $\mathrm{Su}(\mathrm{H})$ increased the availability for activator complex formation sufficient for increased Notch activity. Notably, no altering of Notch targets $v g^{B E}$-lacZ or wg was observed when $\mathrm{Su}(\mathrm{H})^{\mathrm{LLL}}$ was overexpressed together with SPTM- $\mathrm{H}^{\text {myc }}$, in contrast to wild-type $\mathrm{Su}(\mathrm{H})$ (Figure $\left.7 \mathrm{c}, \mathrm{c}^{\prime}\right)$. I propose that SPTM- $\mathrm{H}^{\text {myc }}$ is able to sequester wild-type $\mathrm{Su}(\mathrm{H})$ but not $\mathrm{Su}(\mathrm{H})^{\mathrm{LLL}}$, thereby reducing availability of $\mathrm{Su}(\mathrm{H})$ protein, thereby limiting Notch activity.

The subcellular distribution of SPTM- $\mathrm{H}^{\mathrm{myc}}$ and $\mathrm{Su}(\mathrm{H})$ was analyzed in greater detail (Figure 8). Clearly, both proteins accumulated in the periphery of nuclei (Figure 8a, arrow and Figure 8b, asterisk). Whereas SPTM- $\mathrm{H}^{\text {myc }}$ appeared to be there exclusively, $\mathrm{Su}(\mathrm{H})$ was less well-distinguished and more evenly distributed also in the cytoplasm (Figure 8a). This distribution was especially well-dissolved in comparing different confocal sections in imaginal wing discs (Figure $8 b, b^{\prime}$ ). The abundance of $\mathrm{Su}(\mathrm{H})$ protein differed from apical to basal level: it was primarily enriched in lower sections (8-12), overlapping and adjacent to SPTM-H ${ }^{\text {myc }}$ (Figure $\left.8 b^{\prime}\right)$. In more apical sections, $\mathrm{Su}(\mathrm{H})$ was fully co-localized with SPTM- $\mathrm{H}^{\text {myc }}$, seen as pink mix of $\mathrm{Su}(\mathrm{H})$ blue and SPTM- $\mathrm{H}^{\text {myc }}$ red colors (Figure $8 \mathrm{~b}^{\prime}$ ). The cytoplasmic $v g^{\mathrm{BE}}$-lacZ staining (green, asterisk) was repressed in the omb domain (Figure $\left.8 b, b^{\prime}\right)$.

\subsubsection{Phenotypic Consequences of Co-Overexpression of SPTM- $\mathrm{H}^{\mathrm{myc}}$ and $\mathrm{Su}(\mathrm{H})$}

The consequences of the combined overexpression of SPTM- $\mathrm{H}^{\text {myc }}$ and $\mathrm{Su}(\mathrm{H})$ on fly development were analyzed. The driver line pnr-Gal4 was used, driving expression in the central part of the developing notum and the head [54]. Several defects were noted, mostly affecting growth and bristle formation on the thorax. Overexpression of the SPTM-GFP control with pnr-Gal4 at $25{ }^{\circ} \mathrm{C}$ caused a mild disorganization of the bristles on the thorax (asterisk in Figure 9a) without affecting bristle structure (Figure $\left.9 \mathrm{a}^{\prime}, \mathrm{a}^{\prime \prime}\right)$. $\mathrm{Su}(\mathrm{H})$ overexpression impeded fusion of the imaginal discs, resulting in a deep cleft in the center of the thorax, presumably as a result of extreme over-proliferation of the tissue (Figure $9 \mathrm{~b}-\mathrm{b}^{\prime \prime}$ ). In addition, bristle formation was completely abolished. These flies were unable to hatch and had to be freed from the pupal case for analysis. The ectopic expression of the $\mathrm{Su}(\mathrm{H})^{\mathrm{LLL}}$ mutant, which is unable to bind Hairless, also induced massive over-proliferation accompanied by a complete bristle loss, however, did not affect dorsal fusion nor eclosion (Figure 9c-c").

A dorsal cleft resulted from the overexpression of SPTM- $\mathrm{H}^{\text {myc }}$ (Figure 9d). Moreover, bristle defects were observed, for example, bristle duplications or a partial transformation of socket to shaft cell type affecting microchaetae, as well as loss of macrochaetae (Figure 9d-d"). In combination with $\mathrm{Su}(\mathrm{H}), \mathrm{SPTM}-\mathrm{H}^{\text {myc }}$ impeded dorsal fusion, resulting in a deep dorsal cleft on the thorax. The tissue appeared folded from over-proliferation, however, not well-differentiated, accompanied by a complete absence of all bristles (Figure 9e). At best, some remnants of bristles or trichomes were spotted (Figure 9e', $\mathrm{e}^{\prime \prime}$ ). However, the flies hatched, whereas the sole overexpression of $\mathrm{Su}(\mathrm{H})$ caused pharate lethality. This is a remarkable rescue, corroborated by the less pronounced over-proliferation (compare Figure $9 \mathrm{~b}, \mathrm{e})$, that demonstrates the ability of SPTM- $\mathrm{H}^{\text {myc }}$ to sequester $\mathrm{Su}(\mathrm{H})$, thereby mitigating its activity. In contrast, the co-expression of SPTM- $\mathrm{H}^{\mathrm{myc}}$ with $\mathrm{Su}(\mathrm{H})^{\mathrm{LLL}}$ was not much different from the sole $\mathrm{Su}(\mathrm{H})^{\mathrm{LLL}}$ overexpression: a dramatic overgrowth of the thorax, which was completely naked, was observed (Figure $9 \mathrm{f}-\mathrm{f}^{\prime \prime}$ ). This result confirmed my prediction, since SPTM- $\mathrm{H}^{\mathrm{myc}}$ is unable to 
bind and trap $\mathrm{Su}(\mathrm{H})^{\mathrm{LLL}}$ and, hence, should not influence its activity. Overall, the experiments show that overexpression of SPTM- $\mathrm{H}^{\text {myc }}$ confounds the activity of ectopic $\mathrm{Su}(\mathrm{H})$, which is apparent when comparing the effects with $\mathrm{Su}(\mathrm{H})^{\mathrm{LLL}}$, that is unaffected by SPTM-H ${ }^{\text {myc }}$.
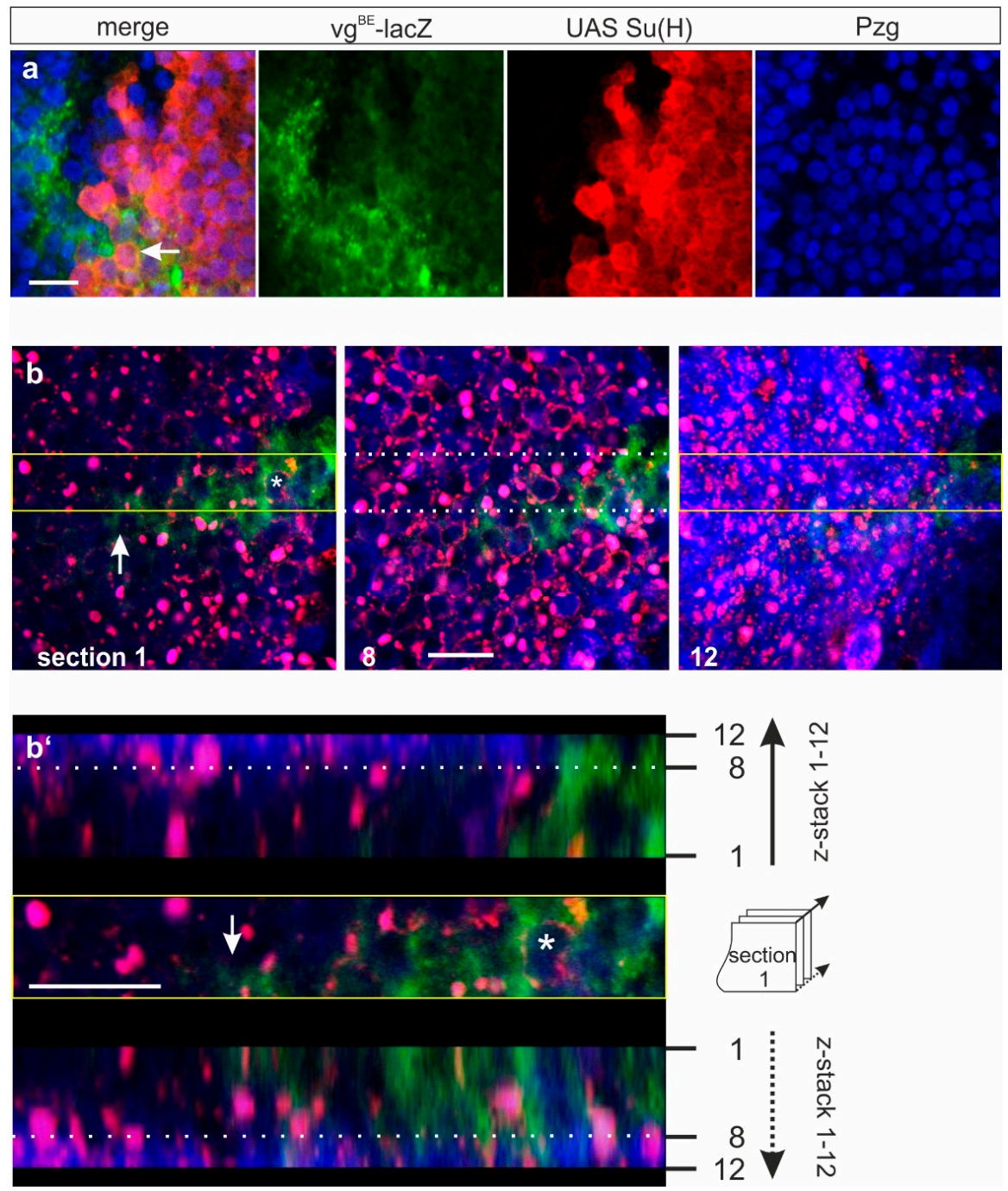

Figure 8. Co-localization of concurrently overexpressed $\mathrm{SPTM}-\mathrm{H}^{\mathrm{myc}}$ and $\mathrm{Su}(\mathrm{H})$ protein. Combined overexpression of $\mathrm{SPTM}-\mathrm{H}^{\mathrm{myc}}$ and $\mathrm{Su}(\mathrm{H})$ in wing discs using omb-Gal4. Enlargements show details of subcellular expression; the size bars represent $10 \mu \mathrm{m}$. (a) $\mathrm{Su}(\mathrm{H})$ protein (red) accumulated outside of the nucleus marked with Pzg antibodies (blue), overlapping $v g^{B E}$-lacZ staining (green) (arrow in the merge picture); $\left(\mathbf{b}, \mathbf{b}^{\prime}\right)$ Z-stack analysis to reveal the uneven distribution of the $\mathrm{Su}(\mathrm{H})$ protein (blue). SPTM-H $\mathrm{H}^{\text {myc }}$ was detected in red, and the $\mathrm{gg}^{B E}$-lacZ reporter in green. Three sections are shown, representing the upper, middle, and lower part $(1,8,12)$ of a $4.8 \mu \mathrm{m}$ thick tissue. The area marked by a yellow and dotted line was compiled to a Z-stack shown in $\left(\mathbf{b}^{\prime}\right)$. Note near-complete overlap of $\mathrm{SPTM}-\mathrm{H}^{\text {myc }}$ and $\mathrm{Su}(\mathrm{H})$ protein (appears pink in the merge) up to section 8. In sections 9 to $12, \mathrm{Su}(\mathrm{H})$ is seen uniformly also outside of SPTM- $\mathrm{H}^{\mathrm{myc}}$ dots, and appears as a blue smear. The asterisk labels a nucleus, encircled by SPTM- $\mathrm{H}^{\text {myc }}$ plus $\mathrm{Su}(\mathrm{H})$ protein. The cytoplasmic $v g^{\mathrm{BE}}$-lacZ staining (green) is repressed in the omb-domain (arrow in $\mathbf{b}, \mathbf{b}^{\prime}$ ). 

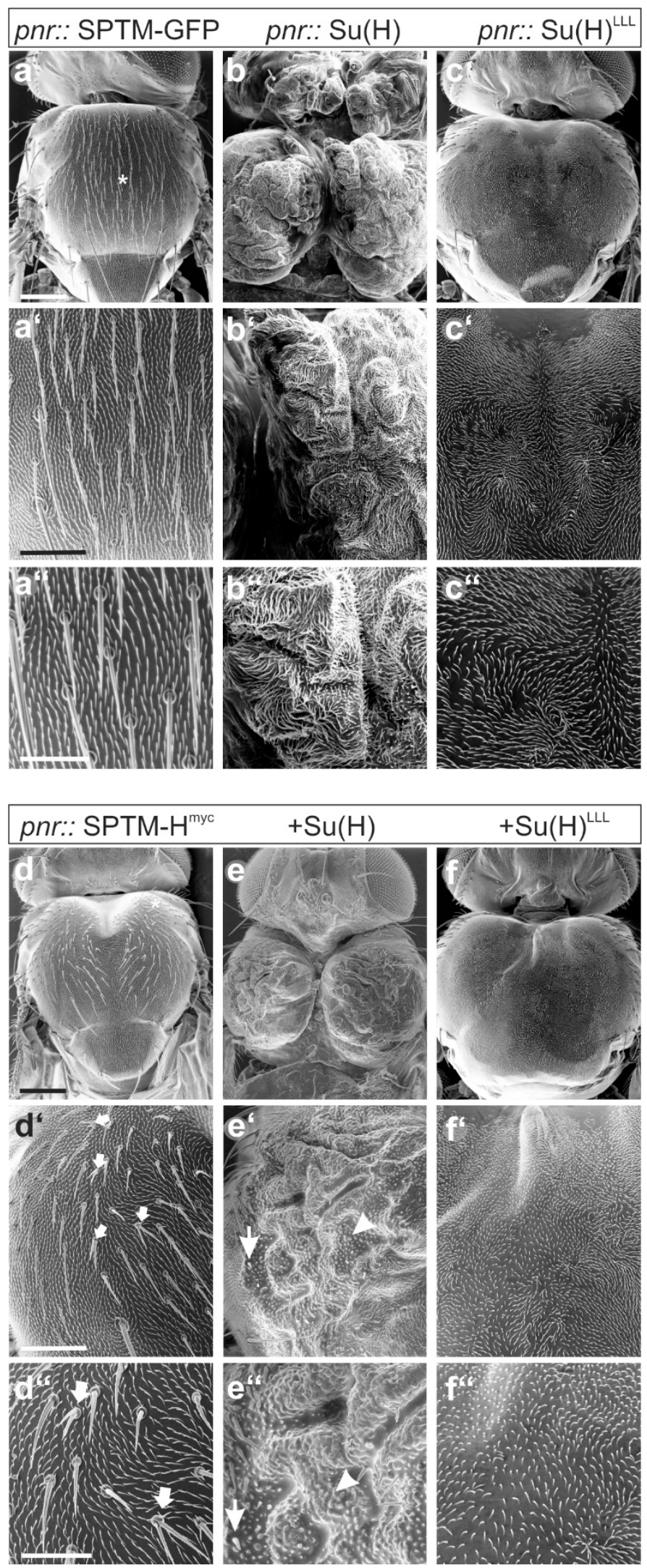

Figure 9. Developmental consequences of the combined overexpression of SPTM-Hyc and $\mathrm{Su}(\mathrm{H})$. Scanning electron micrographs of animals, where the given UAS constructs were induced during development using $p n r$-Gal4 at $25^{\circ} \mathrm{C}$. (a-a") SPTM-GFP control. Note slightly erratic bristle arrangement 
(asterisk), but normal structure; (b-b") wild-type $\mathrm{Su}(\mathrm{H})$ caused massive over-proliferation with heavily folded tissue; the whole body is split into two halves separated by a very deep cleft. No bristles developed. The animals died as pharate adults, and were dissected from the pupal case; (c-c') ectopic expression of $\mathrm{Su}(\mathrm{H})^{\mathrm{LLL}}$ caused a massive overgrowth and a complete loss of chaetae without affecting tissue fusion; $\left(\mathbf{d}-\mathbf{d}^{\prime \prime}\right)$ the overexpression of SPTM- $\mathrm{H}^{\text {myc }}$ affected growth, resulting in a furrow in middle of the thorax and disturbing the orientation of the microchaetae. Moreover, bristles were duplicated, and a partial socket to shaft transformation was observed (small arrows in $\left.\mathbf{d}^{\prime}, \mathbf{d}^{\prime \prime}\right)$; (e-e $\left.\mathbf{e}^{\prime \prime}\right)$ overexpressed in combination with $\mathrm{Su}(\mathrm{H})$, the flies hatched but displayed a deeply cleft thorax with strongly folded, over-proliferated tissue. Small bulges on the surface may be rudiments of bristle structures (arrowhead), as remains of shafts were present at the boundary to unaffected tissue (e', $\mathbf{e}^{\prime \prime}$, arrow); $\left(\mathbf{f}-\mathbf{f}^{\prime \prime}\right)$ the co-overexpression of SPTM-H ${ }^{\text {myc }}$ with $\mathrm{Su}(\mathrm{H})^{\mathrm{LLL}}$ was nearly indistinguishable from the sole $\mathrm{Su}(\mathrm{H})^{\mathrm{LLL}}$ overexpression: the thorax was overgrown with no bristle structure left. Scale bar, $200 \mu \mathrm{m}$ in $(\mathbf{a}-\mathbf{f}), 100 \mu \mathrm{m}$ in $\left(\mathbf{a}^{\prime}-\mathbf{f}^{\prime}\right)$, and $50 \mu \mathrm{m}$ in $\left(\mathbf{a}^{\prime \prime}-\mathbf{f}^{\prime \prime}\right)$.

\section{Discussion}

In this study, the consequences of a Hairless protein lacking the capacity to enter the nucleus were examined. By fusing Hairless to a transmembrane domain, the protein was immobilized at membranes. The type I transmembrane domain and the N-terminal signal peptide were taken from the Delta protein [55], fusing Hairless C-terminally to be directed into the cytoplasm. A Myc-tag allowed the specific detection of the subcellular localization of SPTM- $\mathrm{H}^{\text {myc }}$ protein, clearly distinguishable from the endogenous Hairless protein. In contrast to the wild-type protein, SPTM- $\mathrm{H}^{\mathrm{myc}}$ is not nuclear [28-30]. Instead, it primarily accumulates at the periphery of the nucleus along the nuclear envelope. The punctuate pattern suggests enrichment in the endoplasmic reticulum, whereas larger dots further apart may correspond to the Golgi compartment, confirmed by an overlap of SPTM- $\mathrm{H}^{\text {myc }}$ with two Golgi markers. Accumulation at the outer plasma membrane was less pronounced, though. Nevertheless, the expression pattern demonstrates that SPTM- $\mathrm{H}^{\mathrm{myc}}$ is anchored at membranes as desired.

Indeed, overexpression of membrane-anchored SPTM-H $\mathrm{H}^{\text {myc }}$ resulted in a downregulation of Notch activity. This effect was predicted in case of sequestering $\mathrm{Su}(\mathrm{H})$ by Hairless at the membrane, reducing its availability for activated Notch ICN, and hence activator complex formation and nuclear import (Figure 10a,b). The data confirm earlier findings that binding between Hairless and $\mathrm{Su}(\mathrm{H})$ indeed occurs in the cytosol before the nuclear translocation of the two proteins by Hairless [28,29]. Whether the entire repressor complex pre-assembles in the cytosol, or whether the co-repressors Gro and $\mathrm{CtBP}$ are recruited in the nuclear compartment, remains unknown. The same holds true for the activator complex: whereas it is clear that ICN binds $\mathrm{Su}(\mathrm{H})$ in the cytoplasmic compartment, assembly of the activator complex may occur only on the DNA [3,18,56-58].

As predicted by a downregulation of Notch activity, SPTM- $\mathrm{H}^{\text {myc }}$ overexpression affected tissue growth, as well as the formation of mechano-sensory organs and wing veins (Figure 4). It should be noted, however, that the intimate relationship between Notch and EGFR (epidermal growth factor receptor) signaling pathways opens up the possibility that some of the phenotypes or parts thereof result from an influence of SPTM- ${ }^{\text {myc }}$ on EGFR signaling activity [59-61]. Notably, the ectopic veins induced by SPTM- $\mathrm{H}^{\text {myc }}$ overexpression (Figure 4 b) could as well result from a gain of EGFR function [62-66]. Similarly, both tissue growth and apoptosis are regulated by EGFR as well [49-51,59,67-69]. 
a

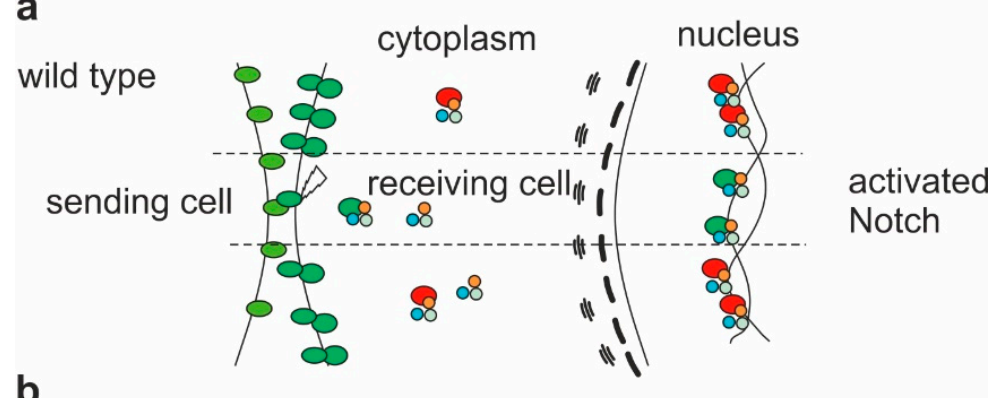

b

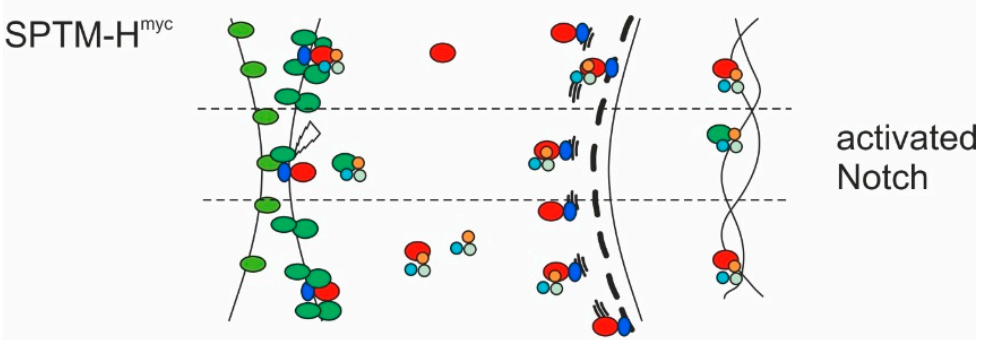

C

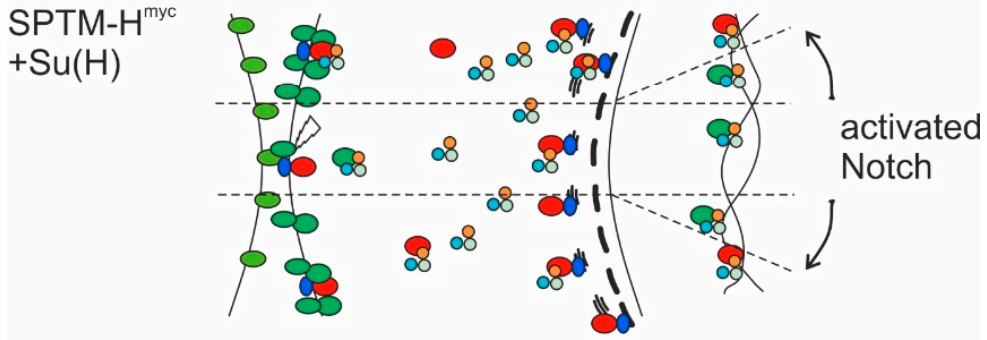

d
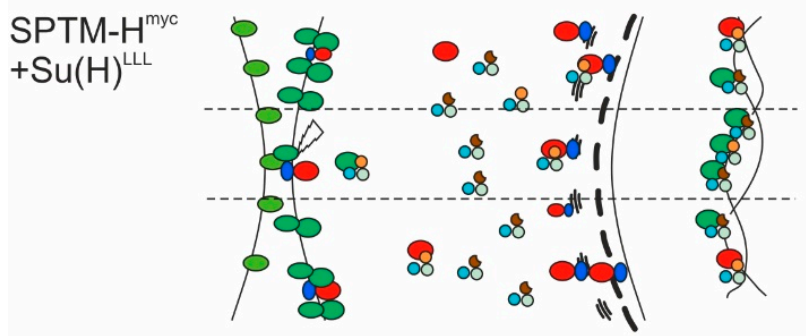

activated

Notch
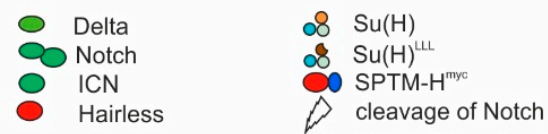

NI ER, Golgi and nuclear envelope

Figure 10. Model of SPTM-H ${ }^{\text {myc }}$ activity. (a) Wild-type situation of Notch signaling pathway: ligands like Delta activate Notch, releasing the intracellular Notch domain (ICN). On its way to the nucleus, ICN binds to $\mathrm{Su}(\mathrm{H})$ in the cytoplasm. Together with other activator molecules, this complex activates the Notch target genes. Outside the Notch activation domain (dashed lines), the process is antagonized by Hairless, which binds $\mathrm{Su}(\mathrm{H})$ in the cytoplasm and transports it in the nucleus, where, together with co-repressors, it forms a repressor complex to silence Notch target genes; (b) SPTM-H $\mathrm{H}^{\text {myc }}$ integrates into membranes (cell membrane and ER and/or Golgi), sequestering freely available $\mathrm{Su}(\mathrm{H})$. Consequently, less activator and repressor complexes are present on the DNA. Since the ratio between activation and repression remains almost unchanged, little phenotypic consequences are observed. Yet, a slight downregulation of Notch activity indicates reduced availability of $\mathrm{Su}(\mathrm{H})$ for recruitment by $\mathrm{ICN}$; c) Overexpression of both, SPTM-H $\mathrm{H}^{\mathrm{myc}}$ and $\mathrm{Su}(\mathrm{H})$, gives a mixed result: repression of Notch targets at places of highest Notch activity, and activation of (Notch targets elsewhere. The former may reveal insufficient availability of $\mathrm{Su}(\mathrm{H})$ due to sequestration by 
SPTM-H $\mathrm{H}^{\text {myc }}$. The latter may result from recruitment of ectopic $\mathrm{Su}(\mathrm{H})$ into activator complexes by spurious levels of ICN in cells that are normally repressed by $\mathrm{H}$ activity; $(\mathbf{d}) \mathrm{Su}(\mathrm{H})^{\mathrm{LLL}}$ is deficient for the binding of $\mathrm{H}$, here shown by a defective $\mathrm{C}$-terminal domain (brown and clipped, instead of a full orange circle). Ectopic $\mathrm{Su}(\mathrm{H})^{\mathrm{LLL}}$ hence acts independently of SPTM- $\mathrm{H}^{\text {myc }}$, causing a much higher Notch activation than in (c). Note that SPTM- $\mathrm{H}^{\text {myc }}$ is still able to sequester wild-type $\mathrm{Su}(\mathrm{H})$, yet affecting likewise activator and repressor complexes as in $(\mathbf{b})$.

The effects of the concurrent overexpression of SPTM- $\mathrm{H}^{\text {myc }}$ and $\mathrm{Su}(\mathrm{H})$, however, are less clear, and quite different from the ectopic expression of the wild-type proteins. The latter combination induces massive cell death in the affected tissues in addition to a strong repression of Notch target genes $[26,52,53,69]$. In contrast, the co-expression of $\mathrm{Su}(\mathrm{H})$ with $\mathrm{SPTM}-\mathrm{H}^{\text {myc }}$ lead to a strong over-proliferation and expansion of Notch target gene expression on the one hand, and to a repression of Notch targets along the dorso-ventral boundary, on the other hand. Hence, a mixed response was observed: a more general activation of Notch signaling output, and a rather specific repression at places of highest Notch activity (Figure 7, Supplementary Figures S3 and S4). One possible explanation is the following: within the zone of highest Notch activation, i.e., along the dorso-ventral boundary, $\mathrm{Su}(\mathrm{H})$ levels are limiting for full Notch activity, because of the sequestering by membrane anchored Hairless (Figure 10b). Accordingly, a decrease of Notch target gene expression is expected. Outside of the Notch-activity zone, ectopic $\mathrm{Su}(\mathrm{H})$ becomes now available for activator-complex assembly, resulting in a weak overall activation of Notch target genes (Figure 10c). In the normal context, $\mathrm{Su}(\mathrm{H})$ is inhibited by endogenous Hairless within this area (Figure 10a), such that spurious levels of activated Notch ICN cannot induce the target genes. In the $\mathrm{Su}(\mathrm{H})$ overexpression context, however, endogenous Hairless levels do not suffice to limit $\mathrm{Su}(\mathrm{H})$ availability and apparently, neither does ectopic SPTM-H $\mathrm{H}^{\mathrm{myc}}$. The low level of activation hints at the fact that $\mathrm{SPTM}-\mathrm{H}^{\mathrm{myc}}$ sequesters $\mathrm{Su}(\mathrm{H})$ to a large degree, but not completely. Excessive $\mathrm{Su}(\mathrm{H})$, however, is able to join with spurious ICN to activate Notch targets at low level overall.

Why then does $\mathrm{SPTM}-\mathrm{H}^{\mathrm{myc}}$ not intercept $\mathrm{Su}(\mathrm{H})$ more strongly, as both are overexpressed concurrently? Perhaps not all of SPTM- $\mathrm{H}^{\mathrm{myc}}$ integrates in the membrane, or the excess of membranecoupled Hairless protein releases an unfolded protein response, albeit no signs of increased apoptosis were observed as expected in case of ER stress [70]. Alternatively, the ICN-Su(H) complex is more stable than the SPTM- $\mathrm{H}^{\text {myc }}-\mathrm{Su}(\mathrm{H})$ complex, allowing ICN to compete for $\mathrm{Su}(\mathrm{H})$ binding. This possibility is supported by the observation that Notch can displace Hairless from $\mathrm{Su}(\mathrm{H})$-Hairless complexes in vitro, despite similar binding affinities in the nanomolar range [26].

In contrast, co-expression of SPTM- $\mathrm{H}^{\text {myc }}$ and $\mathrm{Su}(\mathrm{H})^{\mathrm{LLL}}$ resulted in a different outcome. As $\mathrm{Su}(\mathrm{H})^{\mathrm{LLL}}$ lacks Hairless-binding, increased activator complex formation without repression is expected as a result from excessive $\mathrm{Su}(\mathrm{H})$ availability (Figure 10d). Accordingly, there were little differences regarding the over-proliferation of wing discs with the $o m b$-Gal4 driver or of thoraces with the pnr-Gal4 driver (Figures 7 and 9, Supplementary Figures S4 and S5). No silencing of Notch target genes was observed, however, but rather an enhancement, although SPTM- $\mathrm{H}^{\text {myc }}$ may sequester wild-type Su(H) (Figure 10d).

Adult phenotypes support the interpretation that $\mathrm{Su}(\mathrm{H})^{\mathrm{LLL}}$ largely bypasses interception of SPTM- $\mathrm{H}^{\mathrm{myc}}$, in contrast to wild-type $\mathrm{Su}(\mathrm{H})$. Yet, they also revealed an interesting difference between the wild-type $\mathrm{Su}(\mathrm{H})$ and the H-binding defective $\mathrm{Su}(\mathrm{H})^{\mathrm{LLL}}$ isoforms independent of their interaction with SPTM- $\mathrm{H}^{\text {myc}}$ : whereas both isoforms induced marked over-proliferation within the thorax, $\mathrm{Su}(\mathrm{H})$ but not $\mathrm{Su}(\mathrm{H})^{\mathrm{LLL}}$ impeded dorsal fusion (Figure 9). Dorsal fusion defects may result from interfering with Notch activity and/or from induction of apoptosis [71,72]. In this case, dorsal fusion defects resulting from sole $\mathrm{Su}(\mathrm{H})$ overexpression may be caused by repression of Notch rather than activation, hinting at its Janus-faced role as activator and equally as repressor of Notch targets [5,25-27,53,73]. Similar defects were also induced by the sole overexpression of Hairless [74] and likewise of SPTM-H'Hc (Figure 9), reflecting the limitation of high levels of Notch activity due to reduced $\mathrm{Su}(\mathrm{H})$ availability. Accordingly, dorsal fusion was not improved by the combined overexpression of $\mathrm{Su}(\mathrm{H})$ with $\mathrm{SPTM}-\mathrm{H}^{\mathrm{myc}}$, whereas 
the over-proliferation of the affected tissue was diminished. Over-proliferation, however, is a clear sign of increased Notch activity [50]. These mixed phenotypes, resulting from concurrent overexpression of $\mathrm{SPTM}-\mathrm{H}^{\mathrm{myc}}$ and $\mathrm{Su}(\mathrm{H})$, are reminiscent of the Notch target gene response in imaginal discs-repression at positions of highest Notch activity and induction elsewhere. The defects in tissue differentiation could be a result of either gain or loss of Notch activity. Whether the phenotypic differences can be solely explained by the presented idea, namely that sequestration of $\mathrm{Su}(\mathrm{H})$ by SPTM-H ${ }^{\mathrm{myc}}$ chops the peaks of highest Notch activity, but allows for a general increase of Notch activity outside the normal range, is an interesting question for the future.

\section{Conclusions}

In this work, the major Notch antagonist, Hairless, was expressed as a membrane-anchored protein isoform, impeding its normal function as a transcriptional co-repressor of Notch target genes. Histological analyses demonstrate that membrane-anchored SPTM-H ${ }^{\text {myc }}$ and Su(H) co-localize, indicating that $\mathrm{Su}(\mathrm{H})$ is sequestered and less available for the binding to activated Notch. Accordingly, lowered Notch signaling activity affected lateral inhibition and growth. In contrast, the combined overexpression of $\mathrm{Su}(\mathrm{H})$ and $\mathrm{SPTM}-\mathrm{H}^{\mathrm{myc}}$ enforced Notch signaling activity, reflected by the over-proliferation of tissue and a ubiquitous induction of Notch target gene expression. At the same time, Notch targets were repressed at their normal place of expression, raising the possibility that here, the threshold of highest Notch activity was no longer reached, presumably, because SPTM-H ${ }^{\text {myc }}$ trapped $\mathrm{Su}(\mathrm{H})$, reducing its availability. The work emphasizes earlier findings that $\mathrm{Su}(\mathrm{H})$-Hairless protein complexes are formed in the cytoplasm, and that the binding to Hairless influences the availability of $\mathrm{Su}(\mathrm{H})$ for recruitment by activated Notch ICN.

Supplementary Materials: The following are available online at http://www.mdpi.com/2073-4425/11/11/1315/s1, Figure S1: Construction of the SPTM- $H^{m y c}$ transgene, Figure S2: Sequences of SPTM-H ${ }^{\text {myc }}$ and SPTM-GFP, Figure S3: Effect of the combined activity of SPTM- $\mathrm{H}^{\text {myc }}$ and $\mathrm{Su}(\mathrm{H})$ on Wingless expression, Figure S4: Effect of the combined activity of SPTM- $\mathrm{H}^{\mathrm{myc}}$ and $\mathrm{Su}(\mathrm{H})$ on Cut expression, Figure S5: Effects on the size of the omb-expression domain. References [75] is cited in the supplementary materials.

Funding: This research was funded by a grant MA 1328/11-1 from the Deutsche Forschungsgemeinschaft DFG (http://www.dfg.de) and by the University of Hohenheim. Some Drosophila fly stocks were obtained from the Bloomington Drosophila Stock Center (BDSC), funded by the National Science Foundation (NIH P40OD018537) (https://www.nih.gov). Some of the antisera used in this study were obtained from Developmental Studies Hybridoma Bank (DSHB), developed under the auspices of the National Institute of Child Health and Human Development and maintained by The University of Iowa, Department of Biology, Iowa City, Iowa 52242 (https://www.nichd.nih.gov). Some information was obtained from Flybase, partly funded by the National Human Genome Research Institute (https://www.genome.gov) and the British Medical Research Council (https://mrc.ukri.org).

Acknowledgments: I am indebted to C. Delidakis for providing Delta cDNA, S. Munro and N. Muschalik for providing and sending anti cis-Golgi antibodies. I greatly acknowledge N. Haußmann, I. Preis, T. Mönch and M. Ketelhut for technical help, A. Kuhn for helpful discussion on transmembrane proteins, A.C. Nagel for statistical evaluation, and A. Preiss for text editing.

Conflicts of Interest: The author declares no conflict of interest. The funders had no role in the design of the study; in the collection, analyses, or interpretation of data; in the writing of the manuscript, or in the decision to publish the results.

\section{References}

1. Guruharsha, K.; Kankel, M.; Artavanis-Tsakonas, S. The Notch signalling system: Recent insights into the complexity of a conserved pathway. Nat. Rev. Genet. 2012, 13, 654-666. [CrossRef] [PubMed]

2. Fehon, R.G.; Kooh, P.J.; Rebay, I.; Regan, C.L.; Xu, T.; Muskavitch, M.A.; Artavanis-Tsakonas, S. Molecular interactions between the protein products of the neurogenic loci Notch and Delta, two EGF-homologous genes in Drosophila. Cell 1990, 61, 523-534. [CrossRef] [PubMed]

3. Fortini, M.E.; Artavanis-Tsakonas, S. The Suppressor of Hairless protein participates in Notch receptor signaling. Cell 1994, 79, 273-282. [CrossRef] [PubMed] 
4. Praxenthaler, H.; Nagel, A.C.; Schulz, A.; Zimmermann, M.; Meier, M.; Schmid, H.; Preiss, A.; Maier, D. Hairless-binding deficient Suppressor of Hairless alleles reveal $\mathrm{Su}(\mathrm{H})$ protein levels are dependent on complex formation with Hairless. PLoS Genet. 2017, 13, e1006774. [CrossRef]

5. Bray, S.; Furriols, M. Notch pathway: Making sense of Suppressor of Hairless. Curr. Biol. 2001, 11, R217-R221. [CrossRef]

6. Schweisguth, F. Regulation of Notch signaling activity. Curr. Biol. 2004, 14, R129-R138.

7. Bray, S.J. Notch signalling: A simple pathway becomes complex. Nat. Rev. Mol. Biol. 2006, 7, 678-689. [CrossRef]

8. Kovall, R.A.; Blacklow, S.C. Mechanistic insights into Notch receptor signaling from structural and biochemical studies. Curr. Top. Dev. Biol. 2010, 92, 31-71. [CrossRef]

9. Hori, K.; Sen, A.; Artavanis-Tsakonas, S. Notch signaling at a glance. J. Cell Sci. 2013, 126, $2135-2140$. [CrossRef]

10. Artavanis-Tsakonas, S.; Matsuno, K.; Fortini, M.E. Notch signaling. Science 1995, 268, 225-232. [CrossRef]

11. Bray, S.J. Notch signalling in context. Nat. Rev. Mol. Biol. 2016, 17, 722-735. [CrossRef]

12. Maier, D. The evolution of transcriptional repressors in the Notch signaling pathway: A computational analysis. Hereditas 2019, 156, 5. [CrossRef]

13. Furukawa, T.; Maruyama, S.; Kawaichi, M.; Honjo, T. The Drosophila homolog of the immunoglobulin recombination signal-binding protein regulates peripheral nervous system development. Cell 1992, 69, 1191-1197. [CrossRef] [PubMed]

14. Schweisguth, F.; Posakony, J.W. Suppressor of Hairless, the Drosophila homolog of the mouse recombination signal-binding protein gene, controls sensory organ cell fates. Cell. 1992, 69, 1199-1212. [CrossRef] [PubMed]

15. Hall, D.P.; Kovall, R.A. Structurally conserved binding motifs of transcriptional regulators to Notch nuclear effector CSL. Exp. Biol. Med. 2019, 244, 1520-1529. [CrossRef]

16. Kaspar, M.; Klein, T. Functional analysis of murine CBF1 during Drosophila development. Dev. Dyn. 2006, 235, 918-927. [CrossRef]

17. Gahr, B.M.; Brändle, F.; Zimmermann, M.; Nagel, A.C. An RBPJ-Drosophila model reveals dependence of RBPJ protein stability on the formation of transcription-regulator complexes. Cells 2019, 8, 1252. [CrossRef]

18. Kovall, R.A.; Hendrickson, W.A. Crystal structure of the nuclear effector of Notch signaling, CSL, bound to DNA. EMBO J. 2004, 23, 3441-3451. [CrossRef]

19. Nam, Y.; Sliz, P.; Song, L.; Aster, J.C.; Blacklow, S.C. Structural basis for cooperativity in recruitment of MAML coactivators to Notch transcription complexes. Cell 2006, 124, 973-983. [CrossRef] [PubMed]

20. Wilson, J.J.; Kovall, R.A. Crystal structure of the CSL-Notch-mastermind ternary complex bound to DNA. Cell 2006, 124, 985-996. [CrossRef]

21. Borggrefe, T.; Oswald, F. Setting the stage for Notch: The Drosophila Su(H)-Hairless repressor complex. PLoS Biol. 2016, 14, e1002524. [CrossRef]

22. Maier, D. Hairless, the ignored antagonist of the Notch signalling pathway. Hereditas 2006, 143, $212-221$. [CrossRef]

23. Morel, V.; Lecourtois, M.; Massiani, O.; Maier, D.; Preiss, A.; Schweisguth, F. Transcriptional repression by Suppressor of Hairless involves the binding of a Hairless-dCtBP complex in Drosophila. Curr. Biol. 2001, 11, 789-792. [CrossRef]

24. Barolo, S.; Stone, T.; Bang, A.G.; Posakony, J.W. Default repression and Notch signaling: Hairless acts as an adaptor to recruit the corepressors Groucho and dCtBP to Suppressor of Hairless. Genes Dev. 2002, 16, 1964-1976. [CrossRef] [PubMed]

25. Nagel, A.C.; Krejci, A.; Tenin, G.; Bravo-Patiño, A.; Bray, S.; Maier, D.; Preiss, A. Hairless-mediated repression of Notch target genes requires the combined activity of Groucho and CtBP co-repressors. Mol. Cell. Biol. 2005, 25, 10433-10441. [CrossRef]

26. Maier, D.; Kurth, P.; Schulz, A.; Russell, A.; Yuan, Z.; Gruber, K.; Kovall, R.A.; Preiss, A. Structural and functional analysis of the repressor complex in the Notch signaling pathway of Drosophila melanogaster. Mol. Cell. Biol. 2011, 22, 3242-3252. [CrossRef]

27. Yuan, Z.; Praxenthaler, H.; Tabaja, N.; Torella, R.; Preiss, A.; Maier, D.; Kovall, R.A. Structure and function of the $\mathrm{Su}(\mathrm{H})$-Hairless repressor complex, the major antagonist of Notch signalling in Drosophila melanogaster. PLoS Biol. 2016, 14, e1002509. [CrossRef] 
28. Maier, D.; Nagel, A.C.; Johannes, B.; Preiss, A. Subcellular localization of Hairless protein shows a major focus of activity within the nucleus. Mech. Dev. 1999, 89, 195-199. [CrossRef]

29. Wolf, D.; Smylla, T.K.; Reichmuth, J.; Hoffmeister, P.; Kober, L.; Zimmermann, M.; Turkiewicz, A.; Borggrefe, T.; Nagel, A.C.; Oswald, F.; et al. Nucleo-cytoplasmic shuttling of Drosophila Hairless/Su(H) heterodimer as a means of regulating Notch dependent transcription. Biochim. Biophys. Acta Mol. Cell Res. 2019, 1866, 1520-1532. [CrossRef]

30. Praxenthaler, H.; Smylla, T.K.; Nagel, A.C.; Preiss, A.; Maier, D. Generation of new Hairless alleles by genomic engineering at the Hairless locus in Drosophila melanogaster. PLoS ONE 2015, 10, e0140007. [CrossRef]

31. Lindsley, D.L.; Zimm, G.G. The Genome of Drosophila Melanogaster; Academic Press: San Diego, CA, USA, 1992.

32. Vässin, H.; Vielmetter, J.; Campos-Ortega, J.A. Genetic interactions in early neurogenesis of Drosophila melanogaster. J. Neurogenet. 1985, 2, 291-308. [CrossRef]

33. Maier, D.; Stumm, G.; Kuhn, K.; Preiss, A. Hairless, a Drosophila gene involved in neural development, encodes a novel, serine rich protein. Mech. Dev. 1992, 38, 143-156. [CrossRef] [PubMed]

34. Schweisguth, F.; Posakony, J.W. Antagonistic activities of Suppressor of Hairless and Hairless control alternative cell fates in the Drosophila adult epidermis. Development 1994, 120, 1433-1441.

35. Bland, C.E.; Kimberly, P.; Rand, M.D. Notch-induced proteolysis and nuclear localization of the Delta ligand. J. Biol. Chem. 2003, 278, 13607-13610. [CrossRef]

36. Bischof, J.; Maeda, R.K.; Hediger, M.; Karch, F.; Basler, K. An optimized transgenesis system for Drosophila using germ-line-specific PhiC31 integrases. Proc. Natl. Acad. Sci. USA 2007, 104, 3312-3317. [CrossRef]

37. Brand, A.H.; Perrimon, N. Targeted gene expression as a means of altering cell fates and generating dominant phenotypes. Development 1993, 118, 401-415.

38. Kim, J.; Sebring, A.; Esch, J.J.; Kraus, M.E.; Vorwerk, K.; Magee, J.; Carroll, S.B. Integration of positional signals and regulation of wing formation and identity by Drosophila vestigial gene. Nature 1996, 382, $133-138$. [CrossRef]

39. Maier, D.; Praxenthaler, H.; Schulz, A.; Preiss, A. Gain of function Notch phenotypes associated with ectopic expression of the $\mathrm{Su}(\mathrm{H}) \mathrm{C}$-terminal domain illustrate separability of Notch and Hairless-mediated activities. PLoS ONE 2013, 8, e81578. [CrossRef]

40. Kugler, S.J.; Nagel, A.C. Putzig is required for cell proliferation and regulates Notch activity in Drosophila. Mol. Biol Cell 2007, 18, 3733-3740. [CrossRef] [PubMed]

41. Riedel, F.; Gillingham, A.K.; Rosa-Ferreira, C.; Galindo, A.; Munro, S. An antibody toolkit for the study of membrane traffic in Drosophila melanogaster. Biol. Open 2016, 15, 987-992.

42. Maier, D.; Nagel, A.C.; Preiss, A. Two isoforms of the Notch antagonist Hairless are produced by differential translation initiation. Proc. Natl. Acad. Sci. USA 2002, 99, 15480-15485. [CrossRef]

43. Smylla, T.K.; Preiss, A.; Maier, D. In vivo analysis of internal ribosome entry at the Hairless locus by genome engineering in Drosophila. Sci. Rep. 2016, 6, 34881. [CrossRef]

44. Käll, L.; Krogh, A.; Sonnhammer, E.L. Advantages of combined transmembrane topology and signal peptide prediction-The phobius web server. Nucleic Acids Res. 2007, 35, W429-W432. [CrossRef] [PubMed]

45. Biyasheva, A.; Do, T.V.; Lu, Y.; Vaskova, M.; Andres, A.J. Glue secretion in the Drosophila salivary gland: A model for steroid-regulated exocytosis. Dev. Biol. 2001, 231, 234-251. [CrossRef]

46. Rousso, T.; Schejter, E.D.; Shilo, B.Z. Orchestrated content release from Drosophila glue-protein vesicles by a contractile actomyosin network. Nat. Cell Biol. 2016, 18, 181-190. [CrossRef]

47. Gho, M.; Lecourtois, M.; Géraud, G.; Posakony, J.W.; Schweisguth, F. Subcellular localization of Suppressor of Hairless in Drosophila sense organ cells during Notch signalling. Development 1996, 122, 1673-1682.

48. Milán, M.; Diaz-Benjumea, F.J.; Cohen, S.M. Beadex encodes an LMO protein that regulates Apterous LIM-homeodomain activity in Drosophila wing development: A model for LMO oncogene function. Genes Dev. 1998, 12, 2912-2920. [CrossRef]

49. Go, M.J.; Eastman, D.S.; Artavanis-Tsakonas, S. Cell proliferation control by Notch signaling in Drosophila development. Development 1998, 125, 2031-2040. [PubMed]

50. Estella, C.; Baonza, A. Cell proliferation control by Notch signalling during imaginal discs development in Drosophila. AIMS Genet. 2015, 2, 70-96. [CrossRef] 
51. Slaninova, V.; Krafcikova, M.; Perez-Gomez, R.; Steffal, P.; Trantirek, L.; Bray, S.J.; Krejci, A. Notch stimulates growth by direct regulation of genes involved in the control of glycolysis and the tricarboxylic acid cycle. Open Biol. 2016, 6, 150155. [CrossRef]

52. Kurth, P.; Preiss, A.; Kovall, R.A.; Maier, D. Molecular analysis of the Notch repressor-complex in Drosophila: Characterization of potential Hairless binding sites on Suppressor of Hairless. PLoS ONE 2011, 6, e27986. [CrossRef]

53. Furriols, M.; Bray, S. Dissecting the mechanisms of Suppressor of Hairless function. Dev. Biol. 2000, 227, 520-532. [CrossRef]

54. Fromental-Ramain, C.; Taquet, N.; Ramain, P. Transcriptional interactions between the pannier isoforms and the cofactor U-shaped during neural development in Drosophila. Mech. Dev. 2010, 127, 442-457. [CrossRef]

55. Kopczynski, C.C.; Alton, A.K.; Fechtel, K.; Kooh, P.J.; Muskavitch, M.A. Delta, a Drosophila neurogenic gene, is transcriptionally complex and encodes a protein related to blood coagulation factors and epidermal growth factor of vertebrates. Genes Dev. 1988, 2, 1723-1735. [CrossRef] [PubMed]

56. Vasquez-Del Carpio, R.; Kaplan, F.M.; Weaver, K.L.; VanWye, J.D.; Alves-Guerra, M.C.; Robbins, D.J.; Capobianco, A.J. Assembly of a Notch transcriptional activation complex requires multimerization. Mol. Cell. Biol. 2011, 31, 1396-1408. [CrossRef]

57. Kovall, R.A. More complicated than it looks: Assembly of Notch pathway transcription complexes. Oncogene 2008, 27, 5099-5109. [CrossRef]

58. Bray, S.J.; Gomez-Lamarca, M. Notch after cleavage. Curr. Opin. Cell Biol. 2018, 51, 103-109. [CrossRef]

59. Shilo, B.Z. Signaling by the Drosophila epidermal growth factor receptor pathway during development. Exp. Cell Res. 2003, 284, 140-149. [CrossRef]

60. Doroquez, D.B.; Rebay, I. Signal integration during development: Mechanisms of EGFR and Notch pathway function and cross-talk. Crit. Rev. Biochem. Mol. Biol. 2006, 41, 339-385. [CrossRef] [PubMed]

61. Hasson, P.; Paroush, Z. Crosstalk between the EGFR and other signalling pathways at the level of the global transcriptional corepressor Groucho/TLE. Br. J. Cancer 2006, 94, 771-775.

62. de Celis, J.F. Pattern formation in the Drosophila wing: The development of the veins. Bioessays 2003, 25, 443-451. [CrossRef]

63. Blair, S.S. Wing vein pattering in Drosophila and the analysis of intercellular signaling. Annu. Rev. Cell Dev. Biol. 2007, 23, 293-319. [CrossRef]

64. Sotillos, S.; de Celis, J.F. Interactions between the Notch, EGFR, and decapentaplegic signaling pathways regulate vein differentiation during Drosophila pupal wing development. Dev. Dyn. 2005, 232, 738-752. [CrossRef]

65. Martín-Blanco, E.; Roch, F.; Noll, E.; Baonza, A.; Duffy, J.B.; Perrimon, N. A temporal switch in DER signaling controls the specification and differentiation of veins and interveins in the Drosophila wing. Development 1999, 126, 5739-5747.

66. Johannes, B.; Preiss, A. Wing vein formation in Drosophila melanogaster: Hairless is involved in the cross-talk between Notch and EGF signaling pathways. Mech. Dev. 2002, 115, 3-14. [CrossRef]

67. Wang, C.; Guo, X.; Xi, R. EGFR and Notch signaling respectively regulate proliferative activity and multiple cell lineage differentiation of Drosophila gastric stem cells. Cell Res. 2014, 24, 610-627. [CrossRef]

68. Djiane, A.; Krejci, A.; Bernard, F.; Fexova, S.; Millen, K.; Bray, S.J. Dissecting the mechanisms of Notch induced hyperplasia. EMBO J. 2013, 32, 60-71. [CrossRef] [PubMed]

69. Protzer, C.E.; Wech, I.; Nagel, A.C. Hairless induces cell death by downregulation of EGFR signalling activity. J. Cell Sci. 2008, 121, 3167-3176. [CrossRef]

70. Rasheva, V.I.; Domingos, P.M. Cellular responses to endoplasmic reticulum stress and apoptosis. Apoptosis 2009, 14, 996-1007. [CrossRef]

71. Kockel, L.; Homsy, J.G.; Bohmann, D. Drosophila AP-1: Lessons from an invertebrate. Oncogene 2001, 20, 2347-2364. [CrossRef]

72. Zecchini, V.; Brennan, K.; Martinez-Arias, A. An activity of Notch regulates JNK signalling and affects dorsal closure in Drosophila. Curr. Biol. 1999, 9, 460-469. [CrossRef]

73. Klein, T.; Seugnet, L.; Haenlin, M.; Martinez Arias, A. Two different activities of Suppressor of Hairless during wing development in Drosophila. Development 2000, 127, 3553-3566. 
74. Maier, D.; Chen, A.X.; Preiss, A.; Ketelhut, M. The tiny Hairless protein from Apis mellifera: A potent antagonist of Notch signaling in Drosophila melanogaster. BMC Evol. Biol. 2008, 8, 175. [CrossRef]

75. Zehender, A.; Bayer, M.; Bauer, M.; Zeis, B.; Preiss, A.; Maier, D. Conservation of the Notch antagonist Hairless in arthropods: Functional analysis of the crustacean Daphnia pulex Hairless gene. Dev. Genes Evol. 2017, 227, 339-353. [CrossRef] [PubMed]

Publisher's Note: MDPI stays neutral with regard to jurisdictional claims in published maps and institutional affiliations.

(C) 2020 by the author. Licensee MDPI, Basel, Switzerland. This article is an open access article distributed under the terms and conditions of the Creative Commons Attribution (CC BY) license (http://creativecommons.org/licenses/by/4.0/). 